NBER WORKING PAPER SERIES

\title{
WHAT'S PSYCHOLOGY WORTH? A FIELD EXPERIMENT IN THE CONSUMER CREDIT MARKET
}

\author{
Marianne Bertrand \\ Dean Karlan \\ Sendhil Mullainathan \\ Eldar Shafir \\ Jonathan Zinman \\ Working Paper 11892 \\ http://www.nber.org/papers/w11892 \\ NATIONAL BUREAU OF ECONOMIC RESEARCH \\ 1050 Massachusetts Avenue \\ Cambridge, MA 02138 \\ December 2005
}

University of Chicago Graduate School of Business, NBER and CEPR; Yale University; Harvard and NBER; Princeton University; Dartmouth College. JEL Codes: D01, C93, D12, D14, D21, D81, D91, M37, O12. Keywords: behavioral economics, psychology, microfinance, marketing, field experiment, credit markets. We are extremely grateful to Karen Lyons and Thomas Wang for superb research assistance. We thank seminar participants at CBRSS, Columbia Graduate School of Business, the Econometric Society meetings, Dartmouth, SITE, Harvard, MIT, Berkeley, Yale University, the University of Chicago, the Russell Sage Summer School, Stockholm University, and the Toulouse Conference on Economics and Psychology for many helpful comments. We are especially grateful to David Card, Stefano DellaVigna, Larry Katz and Richard Thaler for many helpful comments. This paper was completed while Zinman was at the Federal Reserve Bank of New York (FRBNY); he thanks the FRBNY for research support and notes that the views expressed are those of the authors and do not necessarily represent those of the Federal Reserve System or the Federal Reserve Bank of New York. We thank the Lender for generously providing us with the data from their experiment. The views expressed herein are those of the author(s) and do not necessarily reflect the views of the National Bureau of Economic Research.

(O2005 by Marianne Bertrand, Dean Karlan, Sendhil Mullainathan, Eldar Shafir, and Jonathan Zinman. All rights reserved. Short sections of text, not to exceed two paragraphs, may be quoted without explicit permission provided that full credit, including $\odot$ notice, is given to the source. 
What's Psychology Worth? A Field Experiment in the Consumer Credit Market

Marianne Bertrand, Dean Karlan, Sendhil Mullainathan, Eldar Shafir, and Jonathan Zinman

NBER Working Paper No. 11892

December 2005

JEL No. D01, C93, D12, D14, D21, D81, D91, M37, O12

\begin{abstract}
Numerous laboratory studies find that minor nuances of presentation and description change behavior in ways that are inconsistent with standard economic models. How much do these context effect matter in natural settings, when consumers make large, real decisions and have the opportunity to learn from experience? We report on a field experiment designed to address this question. A South African lender sent letters offering incumbent clients large, short-term loans at randomly chosen interest rates. The letters also contained independently randomized psychological "features" that were motivated by specific types of frames and cues shown to be powerful in the lab, but which, from a normative perspective, ought to have no impact. Consistent with standard economics, the interest rate significantly affected loan take-up. Inconsistent with standard economics, some of the psychological features also significantly affected take-up. The average effect of a psychological manipulation was equivalent to a one half percentage point change in the monthly interest rate. Interestingly, the psychological features appear to have greater impact in the context of less advantageous offers and persist across different income and education levels. In short, even in a market setting with large stakes and experienced customers, subtle psychological features appear to be powerful drivers of behavior. The findings pose a challenge for the social sciences: they suggest that psychological nuance matters but may be inherently difficult to predict given the impact of context. Successful incorporation of psychological features into field studies is likely to prove a vital, but nontrivial, addition to the formation of more general theories on when, why, and how frames and cues influence important decisions.
\end{abstract}

Marianne Bertrand

University of Chicago

Graduate School of Business

5807 South Woodlawn Avenue

Chicago, IL 60637

and NBER

marianne.bertrand@chicagogsb.edu

Dean Karlan

Institution for Social and Policy

Studies

Yale University

P.O. Box 208209

New Haven, CT 06520-820927

dean.karlan@yale.edu

$\begin{array}{ll}\text { Sendhil Mullainathan } & \text { Jonathan Zinman } \\ \text { Harvard University } & \text { Department of Economics } \\ \text { Department of Economics } & \text { Dartmouth College } \\ \text { Littauer 208 } & \text { 314 Rockefeller } \\ \text { Cambridge, MA 02138 } & \text { Hanover, NH 03755 } \\ \text { and NBER } & \text { jzinman @ dartmouth.edu }\end{array}$

Eldar Shafir

Green Hall

Princeton University

Princeton, NJ 08544

shafir@ princeton.edu 


\section{Introduction}

Neoclassical consumer choice models presume individual rationality. Important decisions are made by weighing costs and benefits with respect to stable preferences. Psychology, in contrast, emphasizes the importance of context and cognitive limitations. Preferences are malleable, and bounded rationality makes problem-solving conflicted and error-prone. A growing body of evidence from laboratory psychology experiments supports this view of consumer choice. It suggests that choices can be manipulated by frames, cues, and other "features" of a choice set that change the presentation of the choice, but not its content or inherent value. ${ }^{1}$

Economists are often skeptical of the external validity of findings from laboratory experiments. Critiques tend to emphasize that lab studies typically use non-representative and inexperienced subjects, small stakes, relatively static environments, and inherently artificial settings that do not extrapolate readily to the "real world (for a recent elaboration of these criticisms, see Levitt and List, 2005). Consequently, several recent studies have looked for violations of neoclassical consumer choice models in observational data from the field. ${ }^{2}$ But few field studies so far have taken the strength of the laboratory methodology - a carefully controlled research design featuring random assignment and precise manipulation of specific treatments - to test for systematic deviations from neoclassical consumer choice. ${ }^{3}$

Even the marketing literature, which presumably stands to gain considerably from measuring the relative influence of psychological and economic treatments on consumer choices, has a dearth of field experiments (Simester 2004), a few notable exceptions being Dreze, Hoch and Purk (1994), Ganzach and Karsahi (1995), Dhar and Hoch (1996), and Wansink, Kent and Hoch (1998). ${ }^{4}$ Con-

\footnotetext{
${ }^{1}$ There are several reviews of this evidence; see, e.g., Camerer, Loewenstein, and Rabin (2004), Cialdini (2001), or Ross and Nisbett (1991).

${ }^{2}$ Related work on household finance in real-world settings includes Odean (1998), who finds that demand for an asset can be influenced by reference points and subtle cues. Iyengar and Jiang (2003) find that choice overload demotivates savings decisions. Chan and Stevens (2004) show that information deficiencies (on pension plan provisions) impact savings behavior. Ameriks, Caplin, and Leahy (2003) find that consumers often lack the willpower to solve a complex problem upon recognizing it. Finally, Thaler and Benartzi (2004) and Ashraf, Karlan, and Yin (2006) report evidence that is consistent with missing markets for commitment devices that facilitate saving in the face of self-control problems.

${ }^{3}$ Notable exceptions can be found on John List's website, http://www.arec.umd.edu/fieldexperiments

${ }^{4}$ Simester writes: "What we usually see in the marketing literature is the results of experiments conducted on college students or analyses of historical data collected from public or proprietary sources. There has been a striking absence of field tests in which companies deliberately vary how they interact with customers engaged in real transactions and measures the response." While some firms are known to conduct systematic experiments on marketing techniques, these results are typically kept private (Day, 2003).
} 
joint analysis, which is by far the most widely used tool by marketing researchers to assess how different bundles of attributes for a product (such as price, packaging or marketing) are preferred by customers, is typically conducted through hypothetical surveys in academic or corporate laboratories (Green, Krieger, and Wind, 2001). ${ }^{5}$

This paper tests for the existence of psychological deviations from a neoclassical consumer choice model using a large scale field experiment. ${ }^{6}$ A consumer lender in South Africa (the "Lender") mailed over 50,000 loan offers to former clients containing randomly assigned psychological features (marketing treatments). The borrowing decision involves high stakes for these consumers, as interest rates are very high (from 50 to $200 \%$ APR) and the median loan size is about one-third of the borrower's monthly gross income.

A unique feature of the experimental design is that we can price any effects of psychological features on loan demand. The Lender simultaneously randomized interest rates that were orthogonal to the marketing treatments. As such, we can scale sensitivity to marketing treatments by sensitivity to interest rates and thereby price psychology. Specifically, suppose that some psychological feature increases take up by $x$ and a one point decrease in interest rate raises take up by $y$. Then the ratio $\frac{x}{y}$ measures the economic importance of this psychological feature: how large a change in interest rate is needed to produce the same size effect.

We designed the marketing treatments to mimic cues and frames that have been shown to influence choice in the lab. For example, we varied whether the Lender's rate was compared to a competitor's (thereby establishing a reference level), and whether this comparison was presented as a loss or a gain. We also experimented with suggested loan uses and with the addition of photographs to the loan offer letter, since psychology has found that cues can be used to arouse emotions that are conducive to consumption. None of the marketing treatments changed the economic terms of the loan offer; they only varied the fashion in which the loan offer was presented. The consumers in our study are experienced borrowers (the median client has three prior loans from the Lender) so it is unlikely that they sought to infer anything about the economic content of the offer from its presentation. ${ }^{7}$

\footnotetext{
${ }^{5}$ In fact, Ding, Grewal and Liechty (2005) test the accuracy of the standard hypothetical conjoint analysis approach by comparing it in the field to an incentive-aligned choice approach and find that the standard conjoint analysis performs considerably worse in predicting actual behavior.

${ }^{6}$ A natural field experiment in the taxonomy put forth in Harrison and List (2004).

${ }^{7}$ We discuss in more detail attempts at reconciling our findings with neoclassical models in Section 6.
} 
We tried ten types of "psychological" treatments that have been shown to impact demand in prior - mostly lab - settings. There is evidence that four of them had significant effects in the full sample. Two additional treatments significantly change demand in meaningful sub-samples. The magnitude of the effects, relative to the demand elasticity with respect to price, is large; e.g., displaying a single example loan rather than multiple ones increased demand by $9 \%$, the equivalent of a 2.3 percentage point decrease in the monthly interest rate.

We also report on several additional findings that speak to how our main results may play out in general equilibrium. First, demand-inducing psychological features appear relatively more effective when the interest rate is relatively high. In other words, it appears that psychological factors matter more for less attractive offers. ${ }^{8}$ Second, there is no discernible difference in the effect of the marketing treatments across income or education groups. Third, credit bureau data suggests that psychological features might induce net new borrowing as there is no evidence that other sources are crowded-out. Fourth, marginal borrowers brought in by the marketing treatments do not appear to be worse default risks. ${ }^{9}$

In all, we find some violations of the neoclassical model that appear to be economically important. More constructively, our findings are consistent with an important role for psychology in market contexts, and lend support to behavioral models of consumer choice that incorporate frames (e.g. Kahneman and Tversky, 1979), cues (e.g., Laibson, 2001), and bounded rationality (e.g., Simon, 1955). Moreover, the fact that many psychological features did not have statistically significant effects demonstrates the importance of context in understanding and predicting when certain laboratory findings will hold in the real world. Incorporating psychological features into field studies will be a challenging but necessary step for forming more general theories on when, why and how such manipulations influence important real decisions.

\footnotetext{
${ }^{8}$ Though since our range of price variation covers only rates that are at and below the Lender's standard ones, we cannot test whether marketing could also be used to induce take up of above-market offers.

${ }^{9}$ This contrasts with adverse selection on price in this market identified by Karlan and Zinman (2005a). Ausubel (1999) also finds evidence of adverse selection in the U.S. credit card market using data from a field experiment.
} 


\section{Background: The South African Credit Market}

\subsection{The Market}

The consumer credit market in South Africa is distinct from most other developing countries in that there is a large, for-profit industry segment extending "cash loans" to individuals with verifiable employment. These lenders offer small, high-interest, short-term credit with fixed repayment schedules to a "working poor" population estimated to comprise anywhere from 2.5 million to 6.6 million people. Cash lenders arose to substitute for traditional "informal sector" moneylenders following deregulation of the usury ceiling in 1992, and they are regulated by the Micro Finance Regulatory Council (MFRC). The MFRC estimates that $65 \%$ of consumer credit in South Africa is delivered by such lenders or by retail stores. Only $3 \%$ of credit to individuals is provided by NGOs, the "typical" governance structure for microfinance in other developing countries (Porteous, 2003), with the remaining $31 \%$ of the South African market delivered by banks or their subsidiaries.

The working poor population lacks the credit history and/or collateralizable wealth needed to borrow from traditional institutional sources such as commercial banks. Loan sizes tend to be small relative to the fixed costs of underwriting and monitoring them, but substantial relative to borrower income; our cooperating Lender's median loan size of R1000 (\$150) is 33\% of its median borrower's gross monthly income. Credit card and mortgage markets are extremely thin in South Africa (and other developing countries) compared to the U.S.

Cash loans are very short-term and expensive relative to credit card or mortgage rates in industrialized nations, although their terms compare favorably to informal sector substitutes in South Africa and elsewhere. Cash lenders focusing on the observably high-risk market segment typically make one-month maturity loans at 30\% interest per month. Lenders targeting observably lower risk segments may charge as little as $3 \%$ per month. ${ }^{10}$ The Lender rejects $50 \%$ of new loan applicants. $^{11}$

\footnotetext{
${ }^{10}$ Note there is essentially no difference between these nominal rates and corresponding real rates, since inflation continues to be quite small relative to these rates (e.g., 10.2\% from March 2002- March 2003 and 10.4\% from March 2003-March 2004).

${ }^{11}$ It is unclear whether these rates correspond to abnormal profits or not, given the difficulty of screening for new clients, and the fixed costs of delivering the loans. It is important to keep this in mind since our sample is a highly pre-screened group of borrowers, having borrowed on average extensively from the Lender in the past.
} 


\subsection{The Lender}

The Lender has been in business for over 20 years and is one of the largest micro-lenders in South Africa, with over 150 branches throughout the country. Our experiment took place in a mix of 86 urban and rural branches throughout the provinces of KwaZulu-Natal, Eastern Cape, Western Cape, and Gauteng. All loan underwriting and transactions are conducted face-to-face in the branch network, with the risk assessment technology combining centralized credit scoring with decentralized loan officer discretion. The Lender's product offerings are somewhat differentiated from competitors. Unlike many cash lenders, it does not pursue collection or collateralization strategies such as direct debit from paychecks or physically keeping bank books and ATM cards of clients. The Lender is also unusually transparent in its pricing, with no surcharges, application fees, insurance premiums, etc., added to the cost of the loan. The Lender also has an unusual "medium-term" product niche, with a large concentration of 4-month loans (85\%). Most other cash lenders focus on 1-month or 18-month loans. ${ }^{12}$ The Lender's standard 4-month rates, absent this experiment, range from $7.75 \%$ to $11.75 \%$ per month, depending on credit history and prior transaction frequency with the Lender. The Lender places no restriction on the use of proceeds from the loan and there is limited evidence as to what the funds borrowed are typically used for.

\section{Experimental Design}

The Lender sent direct mail solicitations to 53,194 former clients offering them a new loan at randomly different interest rates. The solicitations were sent in two mailings, one on September 29-30 and the other on October 29-31. ${ }^{13}$ The rates ranged from $3.25 \%$ to $11.75 \%$ per month. Each letter also contained several marketing manipulations, each randomized independently of the interest rate randomization. Credit approval (i.e., the Lender's decision on whether to offer a loan after updating the client's information) and maximum loan size were orthogonal to the experimental interest rates and marketing manipulations. Since all clients had a prior record with the Lender, $87 \%$ of the applications were accepted, with rejection occurring mostly because of a change in work

\footnotetext{
${ }^{12}$ The Lender does also have 1, 6, 12, and 18-month products, with the longer terms offered at lower rates and restricted to the most observably creditworthy customers.

${ }^{13} \mathrm{~A}$ small pilot to test feasibility was conducted on a separate group of clients in July and included a small subset of these manipulations.
} 
status or other indebtedness. ${ }^{14}$

Receiving mail from the Lender is common for clients. The Lender sends monthly statements to clients via mail, as well as reminder letters to former clients who have not borrowed recently. In the past, these letters have never offered any special deals, interest rates, or marketing tests.

\subsection{The Sample}

The sample frame consisted of all individuals from 86 branches who have borrowed in the past twenty four months, but who did not have a loan outstanding in the thirty days prior to the mailer. ${ }^{15}$ The Lender categorized the sample into three different risk categories, based on the frequency and quality of their prior borrowing history. In the normal course of operations, this risk category determines a borrower's interest rate and loan maturity options. All clients are eligible for 4-month loans, but only the "medium" and "low" risk clients are eligible for 6 and 12 month loans. Because the interest rates used in the experiment are equal to or less than the normal rate, the range of rates for the lower risk clients is smaller than the range for the higher risk clients.

In the analysis below, we breakdown the full sample into two subgroups based on the number of loans a given individual has received from the Lender in the past and on how recently the last loan was received. Specifically, we isolate a subgroup of customers that have borrowed at least twice from the Lender in the past and at least once in the last eight months from those that have not.

Such a breakdown is relevant for our analysis in at least two regards. First, because the Lender does not update its mailing database, we expect the addresses where the offer letters were sent to be more outdated for those individuals who had not borrowed recently. ${ }^{16}$ Second, it is reasonable to suspect that lower frequency borrowers and those who have not taken-up a loan from the Lender recently are less likely to read mail they receive from the Lender. Based on this, we will refer to individuals that have borrowed more often and more recently from the Lender as the "high attention" group; the remaining individuals will be classified as "low attention." 17

\footnotetext{
${ }^{14}$ In the results below, we use loan take-up as the outcome variable. We find very similar results if we use loan application as an alternative left-hand side variable.

${ }^{15}$ This was done because many clients take a new loan out immediately after repaying the prior. The Lender did not want to crowd-out this business they would receive regardless of the offer.

${ }^{16}$ The postal system returns undeliverable mail, and the return rate was $1.51 \%$ for the low risk clients, $2.05 \%$ for the medium risk and $2.68 \%$ the high risk clients.

${ }^{17}$ We have attempted other cuts of the data based on frequency and recency of past borrowing, all of which qualitatively produce similar results. We chose this cut because it most closely resembles the Lender's own internal "risk categories" which summarize the riskiness of the borrower. Specifically, we chose this cut so that the mean
} 
Table 1 reports summary characteristics for the full sample, for the sub-samples of individuals who did and did not take-up on the loan offer, as well as for the sub-samples of "high attention" and "low attention" borrowers.

\subsection{The Randomizations}

Two independent sets of randomizations were conducted. The first set involved the interest rate. Each client was randomly assigned an offer interest rate. ${ }^{18}$ As mentioned before, interest rates varied from $3.25 \%$ per month to $11.75 \%$ per month. ${ }^{19}$ Following the randomization, we verified that the assigned rates were uncorrelated with other known information, such as credit report score.

The second set of randomizations involved the marketing manipulations. We manipulated four broad categories of psychological features: the description of the offer, the comparison of the offer to competitor rates, subtle features (e.g., photos on the letter), and suggestion effects. ${ }^{20}$ Sample offer letters illustrating different subsets of these manipulations are shown in the sample letters in the Appendix. Table 2 reports on the frequency of each marketing manipulation.

\subsubsection{Describing the Loan Offer}

The offer letters presented example loans that differed in interest rate and monthly payment. In the letter, we varied the presentation of the interest rate and the monthly payment for example loans. For some borrowers, the letter presented only a single example of repayment for a given loan maturity and size while for others the letter provided examples of repayment under multiple

differences in frequency and recency matched the differences in frequency and recency between risk groups.

${ }^{18}$ Clients were also assigned a contract interest rate which was equal to or lower than the offer interest rate and was revealed to the client only after they agreed to borrow at the offer interest rate. The contract interest rate is important for a related paper on identifying adverse selection and moral hazard (Karlan and Zinman, 2005a). For the present analysis, we will focus strictly on the offer interest rate, since this is the only interest rate that clients responded to when they decided to borrow.

${ }^{19}$ Note these are "add-on" rates, where interest is charged upfront over the original principal balance, rather than over the declining balance. Such "add-on" rates are conventional in the cash loan market.

${ }^{20}$ We exclude from the discussion altogether two manipulations that were performed at the request of the Lender. One was to include a "We Speak Zulu" blurb in the letter and the other was to describe the rate as "special." Neither produced any effect. We exclude these manipulations from the discussion below as they are of limited academic interest. In this paper, we also do not discuss the impact of the randomly chosen deadlines as well as reminder phone calls. In this paper we do not study the impact of time management manipulations - reminder phone calls and deadlines - in part because changing the deadline changes the economic terms of the offer, making it more difficult to disentangle rational and psychological explanations for the observed behavior. It is discussed in a separate paper (Bertrand et. al. 2005). 
possible terms and/or sizes. ${ }^{21}$ In all cases, the letter explicitly stated that other loan sizes and terms were available. Under the economic model, the simple presentation of multiple examples should have no effect on take-up, or may possibly raise take-up if multiple examples appear to provide more "choices" to the individual or reduce the transaction cost associated with computing repayment rates.

In contrast, behavioral research suggests that a proliferation of alternatives may be detrimental. A greater number of choices may induce decisional conflict and reduce take-up. Psychological studies have shown that people often defer decision, or forego it altogether, when a compelling reason for choosing an option is not readily available and the decision is hard to resolve, compared to when there is a compelling rationale and the decision is easy (Shafir, Simonson, and Tversky, 1993).

In one study, for example, physicians had to decide what medication to prescribe to a patient with osteoarthritis. The physicians were more likely to decline prescribing medication when they had to choose between two comparable medications than when only one of those was available (Redelmeier and Shafir, 1995). A similar pattern was documented with shoppers in an upscale grocery store, who were offered the opportunity to taste any of 6 jams in one condition, or any of 24 jams in another. Of those who stopped to taste, $30 \%$ proceeded to purchase in the 6 -jams condition, whereas only 3\% purchased in the 24-jam condition (Iyengar and Lepper, 2000). In general, decisional conflict advantages the status quo, while departures from the status quo require more psychological justification. ${ }^{22}$

Specifically, with this in mind, we varied the form of a "table" included in the letter that described the offer. We used three different table formats:

1. Big table with 4 different loan amounts, one loan term, 4 monthly repayments and one interest rate. Every client was eligible for this table and $38 \%$ of the entire sample received it. ${ }^{23}$

2. Big table with 4 different loan amounts, 3 loan terms, 4 monthly repayments and 3 interest

\footnotetext{
${ }^{21}$ Karlan and Zinman (2005b) uses random variation in the maturity presented in single-example offer to estimate the sensitivity of loan demand to maturity.

${ }^{22} \mathrm{~A}$ few recent studies report on related patterns with regard to investment decisions. For example, Iyengar, Jiang and Huberman (2003) find lower participation in 401(k) plans that offer a larger number of investment options.

${ }^{23}$ The loan amounts used in the tables were always based on the last loan amount. When multiple amounts were shown, it was always 500, 1000, 2000 and 4000 Rands. The terms used always included 4 months and if multiple terms were shown, also 6 and 12 months.
} 
rates based on the maturity of the loan (all clients had a fixed yield curve). Only "low" and "medium" risk clients were eligible for this table (since only they can receive loans longer than 4 months) and $17 \%$ of the entire sample received it .

3. Small table with one loan size, one loan term, one monthly repayment and one interest rate. Every client was eligible for this table and $44 \%$ received it. ${ }^{24}$

It is important to stress again that all offer letters explicitly mentioned that "Loans were available in other sizes and terms" (a fact most experienced borrowers were most likely aware of already). In other words, we only manipulated here the description of the offer, not its intrinsic content. In practice, we will contrast take-up under a presentation where a single sample loan is displayed in a small "table" (number 3 above), versus presentations where multiple alternative sample loans are displayed (numbers 1 and 2$).{ }^{25}$

\subsubsection{Comparison of Offered Interest Rate to Competitor Rates}

In a subset of the offer letters, we also included a comparison of the offered interest rate to an outside market rate. In a standard economic model, such comparisons should have little effect since the borrower is supposed to be informed about market conditions and, maybe most importantly, since the Lender is not a credible source for the outside market rate. In addition, whether the comparison is framed in terms of perceived savings or losses (e.g. "save if you borrow from us" or "lose if you borrow elsewhere") should not matter for take-up.

Psychologically, however, such framing manipulations can have impact. For example, the presence of a dominated alternative has been shown to increase the market share of the dominating option. Hence, our comparison should increase take-up (Huber, Payne and Puto, 1982). The framing of prospects in terms of losses versus gains can trigger discrepancies in attitudes towards risk, and thereby influence choices. Similarly, because of loss aversion, loss frames may have greater impact on decisions than comparable gain frames, thus potentially leading to greater take-up (Kahneman and Tversky, 1979 and Tversky and Kahneman, 1991).

\footnotetext{
${ }^{24}$ We also varied for some of the letters whether the interest rate was explicitly shown. Twenty percent of the clients (3\% in condition 2 and $17 \%$ in condition 3 above) were simply shown their installment payment and not the interest rate explicitly.

${ }^{25}$ Moreover, the more complicated tables did not in any way obfuscate the rate. It was easy to see the rate since it was explicitly listed in the first column as seen in the Appendix Sample Letter 2.
} 
In practice, we attempted three types of manipulations under the comparison umbrella. First, some letters were assigned randomly to a "comparison" group, for which the offered interest rate was compared to that of a generic (unstated) competitor or to a control group for which no comparison was made. In formulating these comparisons, we use a $15 \%$ interest rate per month as the competitor's offer for four month loans ( $12 \%$ and $11 \%$ for the six and twelve month loans). Second, the comparison was either phrased in terms of savings (a positive frame) or in terms of losses (a negative frame). Third, units were randomized so that savings or losses appeared in either Rand per month, Rand per loan, percentage point differential per month or total percentage point differential per loan. Individuals are accustomed to seeing loan terms described by their monthly payments in Rand, hence we will analysis the results separately for this frame versus the others.

Some examples follow. The positive/negative frame: "If you borrow elsewhere (from us), you will pay R100 Rand more (less) each month on a four month loan." The monthly saving/total saving frame: "If you borrow from us, you will pay R100 (R400) Rand less each month (in total) on a four month loan." The percentage points/total percent frame: "If you borrow from us, your interest rate will be $4.00 \%$ lower!," versus "If you borrow from us, you will pay $32 \%$ less each month on a four month loan."

\subsubsection{Demographic features}

We also experimented with adding a photo (of a pleasant, similing face) in the corner of a random subset of the offer letters. In the standard economic model, such photos should have no effect on take-up. ${ }^{26}$ Psychologically, however, such subtle features can have a large effect. A rich literature on communication and persuasion suggests that the impact of messages can be influenced by source attractiveness, source-recipient similarity, as well as other affective manipulations. Attractive individuals, as well as those more similar to us, are spontaneously attributed more favorable traits, such as talent, intelligence, and honesty, and are more likely to be believed. One study, for example, examined the sales records of insurance companies and found that customers were more likely to buy insurance from a salesperson who was like them in age, religion, politics, etc. (Evans, 1963). When pitted against each other, similarity and attractiveness can prove to be more important than expertise or credibility (see, e.g., Lord, 1997; Cialdini, 2001; Rosenblat and Mobius, 2005, and

\footnotetext{
${ }^{26}$ It is implausible that for customers with so much experience with the Lender that such a photo could provide much information at all.
} 
Landry, Lange, List, Price and Rupp, 2005). In fact, psychological research suggests the primacy of affective over deliberative responses in the context of many decisions (see, e.g., Slovic et al, 2002, for a review.) In one noteworthy recent study of web-based shopping, background pictures and colors were manipulated and found to affect consumer product choices. In one example, involving choice between sofas, a preceding blue background with fluffy clouds led subjects to cite comfort as more important, and later to choose the more expensive and comfortable sofa, compared with those who earlier saw a green background with embedded pennies, and later proceeded to cite price as important and to choose the less expensive sofa (Mandel \& Johnson, 2002). Thus, a photo on the invitation letter may activate affective reactions, most likely inadvertently, that generate a more positive reaction and, consequently, increase take-up.

The photos were manipulated along the lines of race and gender. For race, letters with photos were randomly assigned to "match" or "mismatch." 27 If the client was assigned randomly to "match," then the race of the client matched that of the model on the photograph. For those assigned to mismatch, we randomly selected one of the other two (or three, for Cape Town) races. In order to determine a client's race, we used the race most commonly associated with his/her last name (as determined by employees of the Lender). The gender of the photo was then randomized unconditionally at the individual level. Hence, among the clients that received an offer letter with a photo, half received a photo of the same gender, and half received a photo of the opposite gender.

Ultimately, clients received one of nine variations: no photo (20\%), black male (24.5\%), black female $(24.5 \%)$, coloured male (3.5\%), coloured female (3.5\%), Indian male (6.0\%), Indian female $(6.0 \%)$, white male $(6.0 \%)$, or white female $(6.0 \%){ }^{28}$

Additionally, the race and gender of the person on the photo (if a photo was included) were also matched to the race and gender of the employee name that appeared at the bottom of every letter. Specifically, this name appeared under a section entitled "How to Apply" that told clients to "Bring your ID book and latest pay slip to your usual branch by XX, 2003 and ask for Mr. (Mrs.) XXX," as well as in the signature line. The name used was that of an actual employee.

\footnotetext{
${ }^{27}$ The photos used were either photos that the marketing firm that helped design the letters already had in stock or photos that were commissioned by them for this project.

${ }^{28}$ Coloured are modern-day descendants of slaves from India, Indonesia, Madagascar and Mozambique brought into South Africa by Dutch settlers. Over time they have mixed with Dutch settlers, black South African and the indigenous Khoi and Bushmen. They are found predominately in the Western Cape and this is the only area where photos of a coloured model were included.
} 
In order to apply for a loan, it was not necessary for the client to actually ask for and speak to this person. Customers knew they would merely speak to the loan officer who was available at the time. In cases where no employee in that branch was of the assigned race, then a name from the regional office was used.

\subsection{Promotional Giveaway}

Some companies, including the Lender, regularly use promotional giveaways as part of their marketing. What is the effect of these giveaways on demand? In principle, under the economic model, these should have a small positive or no effect on demand, depending on the magnitude of the prize. In contrast, there is some behavioral evidence that these giveaways could backfire and in fact end up reducing demand. Studies have shown that endowing an option with a feature that is intended to be positive but in fact has no value for the decision maker, can reduce the tendency to choose that option, even when it is understood that the added feature comes at no extra cost (Simonson, Carmon, and O'Curry, 1994). For example, an offer to purchase a Collector's Plate - that most did not want - when buying a particular brand of cake mix, was shown to lower the tendency to buy that particular brand relative to a second, comparable cake mix brand. Choosing brands that offer worthless bonuses was deemed difficult to justify and more susceptible to criticism, with a majority of those who fail to select the bonus option explicitly mentioning not needing the bonus feature. It should be noted that such sale promotions are widely used and there is no evidence that they lead to inferences about the quality of the promoted product (see Shafir, Simonson, and Tversky, 1993, for further discussion.)

To contrast the economic and behavioral perspective, we randomly included in $25 \%$ of the letters the following small announcement: "WIN 10 CELLPHONES UP FOR GRABS EACH MONTH!" Most competitors, as well as this Lender, offer such promotions, monthly or at some other regular interval. Like our promotion, competitors' promotions do not detail the odds of winning or the value of the prize.

\subsubsection{Suggestion Effects}

A final set of manipulations was motivated by the psychological literature on the power of suggestion. For example, several studies have documented the effects of hypothetical questions on 
respondents' subsequent decisions. One line of investigation has shown that people's prediction of their own future behavior, although inaccurate, can affect their subsequent behavior. In one experiment (Sherman, 1980), college students were asked to write counter-attitudinal essays. In a prior, seemingly unrelated survey, half the students were asked to predict whether they would comply with such a request, and many predicted they would not. The eventual rate of compliance among these subjects was much lower than among those who had not made an earlier prediction. Subjects had thus mis-predicted their own behavior (since many would have written the essay had they not been asked to predict). Nonetheless, the actual rate of compliance was very close to that predicted. In effect, people went on to behave in a manner consistent with their own mis-predictions. Related research has shown that such self-erasing errors may be used to increase voter turnout simply by asking people to predict whether they will vote (Greenwald, Carnot, Beach, and Young, 1987; although see Smith, Gerber, \& Orlich, 2003, for a failed replication attempt.).

Faced with relevant questions, even if hypothetical, respondents are unable to prevent a substantial effect on their thoughts and behavior (Fitzsimons and Shiv, 2001). For example, Morwitz et al. (1993) found that merely surveying consumers on whether they intended to purchase items such as automobile or personal computers increased those consumers' subsequent purchase rate of those goods. Follow-up interviews suggest that individuals are unaware of the effects of hypothetical questions on their choices. Consequently, these effects are typically difficult to counteract.

We attempted to test for suggestion effects in this credit market context. A subset of clients from the second mailing wave were chosen randomly (across all risk categories) to receive a phone call from a market research firm in the week prior to the mailing of the offer letters. The individual caller then asked two questions: "Would you mind telling us if you anticipate making large purchases in the next few months, things like home repairs, school fees, appliances, ceremonies (weddings etc), or even paying off expensive debt?" and "Have you considered taking out a cash loan in the coming months?" However, the randomization was not properly implemented. Because of clerical error, the call center did not follow the random list we had created but instead called an arbitrary set of clients. As Table 3 in the Appendix indicates, we cannot find strong systematic differences on observables between the customers the call center attempted to call and those that it did not. However, these results should be interpreted more carefully as they may not be causal.

Somewhat different in nature, a second suggestion manipulation was aimed at influencing the 
usage clients had in my mind when taking up on the loan offer. Every letter was randomly assigned one of five "loan usage" phrases. The phrases were equally divided amongst the letters (i.e. each phrase was given to $20 \%$ of the clients). The most general phrase simply stated: "You can use this cash for anything you want." The other four phrases also contained this text, but in addition listed a more specific goal (pay off a more expensive debt, repair your home, buy an appliance, or pay for school fees). These were the most common uses identified by the Lender in prior market research. Work on mental accounting (e.g., Thaler, 1990) has shown a proclivity to spend selectively from "dedicated accounts." We were specifically interested in whether a given proposed goal increased the proportion of clients who planned to use the loan for the stated purpose.

\section{Basic Results}

\subsection{Overview}

For simplicity and comprehensiveness, we first present results for each manipulation separately. For each manipulation $Z$, we run a probit regression of the type:

$$
\operatorname{Pr}(T=1)=\Phi(a+b * Z+c * r+d * X)
$$

where $T$ is a dummy indicating loan take-up, $r$ is the offered rate and $X$ is a vector of indicator variables for risk category and experimental wave. ${ }^{29}$ If the randomization is conditional on variables other than risk category and experimental wave, these will also be included in the $X$ vector. We also estimate this regression separately for the lower and higher expected attention borrowers. In each Table, we report marginal effects and standard errors. All reported estimated coefficients have been multiplied by 100. So, for example, a coefficient of 0.7 on a dummy variable indicates that turning that dummy variable on increases take-up by 0.7 percentage points.

Also, for each psychological manipulation, we present the "interest rate equivalent" of that manipulation. This appears in brackets under the relevant standard error. It is computed as the ratio of the estimated coefficient on the psychological manipulation to the estimated coefficient on the interest rate in that regression $\left(\frac{b}{c}\right)$. As noted earlier, this quantifies how large of a change in

\footnotetext{
${ }^{29}$ In Appendix Table 1, we estimate the impact of the psychological interventions on loan size, either over the full sample or conditional on take-up. We find no significant effect on loan size conditional on take-up. Thus the impact on the take-up decision summarizes the overall impact on demand.
} 
the interest rate is needed to achieve the same effect on take-up as the psychological manipulation under study.

Two features of take-up are worth pointing out. First, there is much lower take-up among the high risk borrowers (6\%, versus $17 \%$ for low- and medium-risks). As we discussed above, this likely corresponds to the combination of two factors. First, individuals in the high risk group have had less interaction with the Lender and, unlike the lower risk borrowers, may thus be less likely to read the Lender's mailings. Second, the lack of update of the mailing database by the Lender implies that a higher fraction of offer letters in that group were sent to outdated addresses and therefore were never actually received. We are unable to partial out the relative importance of these two explanations. Second, across the full sample, there is a negative and significant impact of the interest rate on take-up. The magnitude indicates that a 1 percentage point drop in the offer interest rate increases take-up by about .26 percentage points (see column 1 of Table 3 ). Given the average take-up rate in the experiment, this implies that a one percentage point drop in the offer interest rate leads to about a 3.5 percent rise in take-up.

\subsection{The Description of the Offer}

Table 3 reports the impact of presenting on the offer letter a table with many choices compared to a table with only one choice. How is the sensitivity of take-up affected by this description of the offer? In column 1, the estimated coefficient on the "small table" dummy is positive and statistically significant. Everything else equal, offer letters displaying a small table generate a .60 percentage point higher take-up than offer letters displaying a large table. In brackets in column 1, we quantify this effect in interest rate terms. Given an estimated coefficient of -.26 on the interest rate for the full sample, our findings suggest that using a simple description for the offer has roughly the same effect on take-up as dropping the interest rate by 2.3 percentage points.

Separate analyses by high versus low attention groups (which, to remind the reader, correspond to borrowing frequency) reveal some differences in point estimates across these groups, though the standard errors do not allow us to reject the null of no differences. In both groups, though, we find a positive effect of the small table description on take-up. In interest rate terms, the estimated effect ranges between 3.6 (for the high attention group) and 1.9 (for the low attention group).

Our finding that more simplicity in the description of the offer increases take-up seems very 
hard to rationalize with traditional economic reasoning. Under the view that consumers have to pay some costs to analyze the value of different potential loans and are trading off the value of their time with the expected value of the loan, one would, if anything, predict a higher take-up under the richer description of the offer, as part of this possibly costly computational work has already been done for the consumer.

\subsection{Comparison of Offer to Competitor Rates}

Our findings on the comparison frame manipulations are reported in Table 4 . We first regress take-up on two indicator variables: whether there was any comparison to the competitor's rate and whether this comparison was expressed as a gain or a loss (columns (1) to (3)). The addition of a comparison has no statistically significant effect on the take-up decision. Similarly, whether this comparison was in a gain or loss frame does not appear to affect take-up.

In columns (4) to (6), we see that this aggregation across different ways of expressing the comparison in the gain and loss frames hides a more complicated story. Specifically, in these columns, we examine the impact of a gain/loss frame as a function of whether the comparison was expressed in monthly rand, monthly percent, total rand or the interest rate itself. The omitted comparison category in these regressions is the one that is the most natural in this populationmonthy rand payments. As we see, for this category, the gain frame is far less effective than the loss frame at inducing take-up. Moreover, the monthly rand comparison also produces the highest take-up overall. The other comparisons induce lower take- and the loss/gain framing also appears irrelevant for these comparisons. These results suggest that the loss frame is quite powerful at increasing take-up, but only when expressed in terms which people are most familiar.

\subsection{Race and Gender features}

Table 5 reports the effect of the race of the person on the photo included in some of the offer letters. As is clear from that table, we find no systematic effect of the race on the photo, and no systematic effect of a match between the race of the photo and client. Putting aside the possibility that the standard errors are too large to yield a behavioral pattern, this lack of a significant effect could have two rather opposing explanations. First, it is possible that racial cues are unimportant in this context. This would be especially intriguing in an environment as racially charged as that 
of South Africa. Alternatively, it is precisely the high salience of race that may have rendered the manipulation powerless. Subtle priming manipulations, such as those attempted by the photos, depend on making salient something that, without being primed, is less so. To the extent that race is ever present in people's minds, then the subtle priming of race is likely to prove of limited consequence.

Table 6 reports on the effect of the gender of the person on the photo. In Panel A, we examine the effect on male and female clients of seeing either the photo of a person of the opposite gender (odd columns) or the photo of a woman (even columns); we also include a dummy variable for whether a photo was included.

Both the "opposite gender" dummy and the "female photo" dummies produce quite large effects on take-up, ranging between 1.3 and 2.2 percentage points in interest rate terms. But the effect of the "opposite gender" dummy is insignificant (relative to the omitted "same gender" category), while the effect of the "female photo" dummy is statistically significant (relative to the "male photo" category) in most specifications. In fact, the "no photo" dummy is positive and significant in 2 of the 3 even column regressions, suggesting that perhaps the largest effect is a negative effect on take-up of including a male photo on the offer letter.

In Panel B, we separate male and female customers. For the male customers, replacing the photo of a male with a photo of female on the offer letter statistically significantly increases takeup; the effect is about as much as dropping the interest rate 4.5 percentage points. For these customers, there is no statistically significant difference between the "no photo" treatment and the "male photo" treatment; however, the point estimates indicate a positive effect of "no photo" relative to "male photo." For female customers, we find no statistically significant patterns.

Overall, these results suggest a very powerful effect on male customers of seeing a female photo on the offer letter. Standard errors however do not allow us to isolate one specific mechanism for this effect. The effect on male customers may be due to either the positive impact of a female photo or the negative impact of a male photo.

\subsection{Promotional Giveaway}

Table 7 describes take-up based on whether or not the letter offered a promotional competition. In the pooled sample (column 1), we find a negative effect of the give-away on take-up though this 
effect is not statistically significant. But when we break down the sample into attention categories, we see that this effect is very large and statistically significant among the more attentive borrowers. For this group of customers, the presence of this promotional feature, which represents a real cost for the Lender, is equivalent to raising the interest rate by nearly 4 percentage points. Hence, consistent with the behavioral findings described above, the addition of this intended-to-be-positive feature in fact reduces the likelihood of loan take-up. The nonnegative effect among lower attention borrowers (column 3) suggests that in this case, the negative impact of the promotional lottery might be offset by an attention-getting effect, which one may expect to be most important for the less attentive customers.

\subsection{Suggestion Effects}

As discussed above, we performed two different "suggestion" randomizations: a suggestion phone call prior to the mailing of the offer letter and the mentioning of different "suggested loan usage" phrases in the offer letter. We report on both of these interventions.

First, a market research firm randomly called a subset of customers prior to their receipt of the letter. In the phone call, they were asked several market research questions such as whether they were interested in borrowing in the future. As noted above, there was a failure of randomization in that the call center devised its own list of people to receive a suggestion phone call. ${ }^{30}$ In addition, only a small fraction of those that the call center attempted to call were eventually reached. The nonrandom implementation of the suggestion call raises the possibility of endogenous selection effects. Accordingly we present results under 3 different empirical approaches: treatment on the treated, treatment on the treated conditioning on a battery of client characteristics, and IV effects (where we instrument the treated dummy with a dummy for whether the call center attempted to reach a given client).

The findings are reported in Table 8. We find extremely large positive effects of the suggestion phone call on take-up, even though the effects are in this case more precisely estimated for the low attention group. In addition, the probit estimates are remarkably robust to adding the vector of controls for observable client characteristics. For the low attention group, the IV estimate is statistically significant and similar in magnitude to the probit estimate.

\footnotetext{
${ }^{30}$ As we already indicated above, we do not find systematic differences on observable characteristics for the customers that the call center attempted to call. See Table 3 in the Appendix.
} 
We next assess whether the suggested loan usage phrases randomly assigned to the offer letters had any impact on the reported usage customers had for the loans they took up. For example, we ask whether clients who were assigned "school fees" as a suggested usage are more likely to plan to use the loan for school-related expenditures. In order to measure customer-specific loan usage, managers at the Lender's branches were required to ask loan applicants what they were going to use the loan for. ${ }^{31}$ While branch managers were supposed to ask this question to all loan applicants, there was substantial non-compliance in practice, so that we have answers to this usage question for only about a third of all taken-up loans. About 19 percent of all surveyed clients reported planning to use the loan for school-related expenditures, 11 percent planned to use it to repay other "accounts" and 11 percent for home-related expenditures. The two next largest usage categories were "personal usage" (17 percent) and "unknown usage" (10 percent). ${ }^{32}$

In Table 9 we examine whether there is a relation between suggested use and reported use. For the set of customers for which we have data, we pool customers into categories based on actual loan usage. Each column reports the proportion breakdown by treatment for each loan usage category. For example, in column (1), we focus on those 154 customers who reported using the loan for house related expenditures. Since $21.02 \%$ of the customers were in the treatment that had suggested a house related use, we would expect $21.02 * 154$ of these customers to come from this treatment category under the null of no suggestion effect. Similarly since $18.63 \%$ received an educational suggestion, we would expect $0.1863 * 154$ of the customers in column 1 to come from this treatment category.

In bold in each cell is the percentage deviation from these expected numbers. For example, among those customers that receive the "house usage" suggestion, there were $3 \%$ more customers who reported using the loan for their house related experiences than would have been expected under the null of no suggestion effect. Similarly, of the 161 customers who reported using the loan to pay off debt, $3.6 \%$ percentage points more came from the "pay off debt" suggestion treatment than would have been expected under the null of no suggestion effect. As one can see from Table 9 , there is a positive excess for each of the suggested specific usage categories. A binomial test of these four excesses produces a p-value of .0587 , hence there is statistically significant evidence of

\footnotetext{
${ }^{31}$ This question was asked after the loan had been approved but prior to the physical handing of cash. This timing ensured that answers to the question could not affect approval, though we cannot rule out that customers may have had this conern.

${ }^{32}$ Very few clients (less than 2 percent) reported planning to use the loan to buy appliances.
} 
an effect of suggested usage on reported usage.

\section{$5 \quad$ Pooling the Manipulations}

We have reported so far on our findings for each of the marketing manipulations separately. To address a set of additional questions, it will be useful to try to pool these manipulations into a single treatment intensity variable. To do so, we label each of the individual manipulations as either a positive or a negative. For each offer letter, we then add the number of positive interventions and subtract the number of negative interventions, thereby computing a total number of net positive interventions. Based on prior beliefs from the psychology literature, we code it as a positive intervention when only one possible example loan is shown, when the offered interest rate is compared to an outside rate, and when a same-race photo (as the client) is included in the offer letter. We code the inclusion of a promotional lottery on the offer letter as a negative. We code the gender of the photo as a positive intervention either when the photo is that of a female, or when it is opposite gender from the client, or both. We ignore the suggestion phone call intervention in the construction of this treatment intensity variable because, as discussed before, these did not fall under the same strict randomization design. ${ }^{33}$ We also ignore the suggested usage manipulation as this manipulation does not relate to influencing the take-up level.

Finally, it will be relevant for some of the analysis that follows (for example, concerning the type of selection operating on the psychological margin) to focus exclusively on those manipulations that "worked," i.e. induced a significant effect on take-up. We therefore also construct a version of the treatment intensity variable that count as zeros those interventions that led to no statistically significant effect on take-up.

\subsection{Basic Results}

Table 10 reports on the effect of these various treatment intensity variables on take-up. Let $P$ be the treatment intensity measure and $T$ denote take-up. We then estimate a probit model of the form:

\footnotetext{
${ }^{33}$ All the findings in the tables that follow are qualitatively unchanged if we include these 2 additional manipulations, coding them as both positive interventions.
} 


$$
\operatorname{Pr}(T=1)=\Phi(a+b * P+c * r+d * X)
$$

where $r$ is the interest rate and $X$ is a vector of controls, including dummies for experimental wave as well as all variables conditional on which the randomization of any of the manipulations in the intensity variable took place (see section 3.2 for details).

Each cell in Table 10 summarizes a separate probit model corresponding to the version of the treatment intensity variable defined by that row and column. Reported in each cell is the estimated marginal effect of that treatment intensity variable on take-up, the standard error on this estimated effect (in parentheses) and the quantification of this effect in interest rate terms (in brackets).

The first column reports the treatment intensity that includes all interventions whereas the second conlumn includes just the statistically significant interventions. The 3 rows of Table 10 correspond to the three different coding of the "photo gender" manipulation, as described above.

When looking at all interventions (the first column of Table 10), we find that every additional positive psychological manipulation corresponds to a drop in the monthly interest rate of between 0.54 to 0.77 percentage points. When just including the statistically significant manipulations (column 2), each additional manipulation corresponds to a drop in the monthly interest rate of between 2.35 and 3.12 percentage points. ${ }^{34}$ Effects are even stronger when looking at just the high attention clients (columns 3 and 4).

\section{$5.2 \quad$ Nonlinearity of Results}

The first additional question we address with this treatment intensity variable relates to how the various psychological manipulations interact with each other in their effect on take-up. Are they substitutes so that having two positive interventions is not twice as strong as having one? Or are they complements, with a given additional intervention reinforcing the effect of the other one? To address this question, we use the versions of the treatment intensity variable that focus on the significant interventions only.

In the first column of Table 11, we simply turn the linear treatment intensity variable into a set

\footnotetext{
${ }^{34}$ Again, as we discuss earlier, these columns 2 and 4 are not meant to be interpreted as representative of the average psychological manipulation as we condition here on selecting only those manipulations that produced a significant effect. Instead, these versions of the treatment intensity variables will be most useful in answering further questions about how the psychological interventions affect take-up.
} 
of dummies that correspond to each separate number of net positive interventions. These individual dummies are estimated with a great deal of noise, preventing us from making any strong inference. However, the pattern of estimated coefficients does not indicate a great deal of nonlinearity.

In column 3 , instead of giving each intervention $a+1$ or -1 in the construction of the treatment intensity variable, we give it a weight equal to its marginal effect as estimated in the single probit regressions above (Tables 3 to 7 ). We then add up these coefficients. This is designed so that a regression of take-up on this new treatment variable should produce a coefficient of 1 . We then include a quadratic term to examine the possibility of a non-linear effect. The point estimate on that quadratic term is positive for all clients (column 3) and negative for high attention clients (column 6), but small in both cases in magnitude and statistically insignificant. Finally, in columns 4 and 7 of Table 11, we study for possible non-linearity by splining the new treatment variable at its median value. The estimated coefficients on the 2 splines are consistently insignificant, just as with the quadratic specifications.

\subsection{Interaction of Psychology with the Interest Rate}

Do the psychological interventions help in generating take-up especially in case of a better deal? Or do they instead help in mitigating the impact of a worse deal?

We start addressing these questions in Table 12. In that table, we report probit models where we relate the take-up dummy to the treatment intensity variable, a dummy variable for whether the offer interest rate is high (which is set to 1 if the offer interest rate is above median in a borrower's risk category), and the interaction of the treatment intensity with this high interest rate dummy. ${ }^{35}$ Irrespective of the treatment intensity variable used to estimate this model, the results in Table 12 show a very clear pattern. The psychological interventions matter more when the interest rate is high. In other words, the psychological manipulations appear to weaken the price sensitivity of demand.

In evaluating these findings, it is important to remember the specifics of our experimental design. In particular, nearly all of the customers in the sample were offered a rate that was more attractive than the rate they would have been eligible for absent this experiment. So, strictly

\footnotetext{
${ }^{35}$ We find qualitatively similar results if we include the continuous interest rate variable instead. The dummy specification simply allows us to more easily factor in the fact that the interest rates were assigned conditional on the risk categories.
} 
speaking, our findings in Table 12 indicate a weaker sensitivity to less favorable deals when the offer is "psychologically" more attractive. We cannot directly answer whether a "psychologically" attractive offer would also lead more people to take-up on financial offers that are unattractive in absolute terms.

There are two main alternative interpretations for the findings in Table 12. On the one hand, it is possible that the psychological interventions make a given individual less price sensitive. Alternatively, it is possible that the psychological interventions lead to higher selection into take-up among those individuals who are the least price sensitive.

We evaluate this second interpretation in Appendix Table 2. To do this, we first assign a predicted price sensitivity to each customer in our sample based on demographic characteristics. Specifically, using the full sample, we regress the take-up dummy on a vector of customer characteristics, the "high interest" rate dummy variable, risk category fixed effects, experimental wave fixed effects, and a full set of interactions between the high interest rate dummy and customer characteristics. ${ }^{36}$ We then compute, for each customer, predicted take-up under high interest rate and predicted take-up under low interest rate, with predicted price sensitivity defined as the difference between those two measures.

We then regress this predicted price sensitivity on the treatment intensity variable, focusing on the sub-sample of customers who have taken up a loan. In other words, we ask whether, among the customers that took up a loan, there is a correlation between their predicted price sensitivity and the psychological attractiveness of the offer letter they were sent. A negative (positive) correlation would mean that the psychological manipulations tended to attract a disproportionate fraction of less (more) price sensitive customers into take-up. These results are reported in Appendix Table 2. In the first column we focus on all interventions, while in the second we focus on the statistically significant interventions. While the point estimates are negative in both columns, the magnitudes are small and insignificant (the mean of the dependent variable is 0.015 , and each additional intervention decreases the predicted price sensitivity by 0.000087 points in Column 1

\footnotetext{
${ }^{36}$ The customer characteristics include: dummy variables for the number of months the client's account at the Lender has been dormant, the logarithm of the number of months the client has been employed at his or her current employer, the logarithm of the client's gross monthly income, the client's credit score (and a dummy variable for the credit score being zero), a gender dummy, a dummy variable for the client having a high education background, dummy variables for the client's province of residence, dummy variables for the client's first language, the client's number of dependents (and a dummy for the client having no dependents), and a dummy variable for a client having both cellular and home phone numbers invalid.
} 
and by 0.0002 in Column 2.). This effect is also very small in comparison to the reduced price sensitivity observed in Table 12. In other words, a selection effect has the potential to explain only a small part of the overall effect.

\subsection{Which Clients Respond More to the Psychological Manipulations?}

Do the psychological interventions influence take-up more for the less educated or lower income customers in our sample? Indeed, one may hypothesize that those customers that are cognitively less sophisticated (as proxied by education or income) may be especially responsive to the psychological features of the offer letter. We examine this question in Table 13. In that table, we allow for the effect of the psychological treatment intensity variables to vary based on whether a given client falls above or below the sample median in terms of predicted education or income. ${ }^{37}$

We find no evidence of a greater response to the psychological features among the less educated or lower income customers. In regressions not reported here, we also considered how sensitivity to the psychological interventions varied based on the level of past experience a given client had with the Lender (which we proxied for by the number of loans the client had had with the Lender in the past). Again, we found no evidence that increased experience reduced sensitivity to psychological manipulation.

In summary, we find no systematic evidence of a dampening of the responsiveness to the psychological features with higher education levels or greater experience with the Lender.

In Table 14, we examine whether the psychological manipulations induce adverse selection by looking at repayment rates on the taken-up loans. Specifically, we construct a new dependent variable that measures the amount past due on the loan as a percentage of the total loan amount. We then ask whether the various psychological treatment intensity variables systematically relate to greater amount past due. Included in all regressions are also the offered interest rate, the contract interest rate (see Karlan and Zinman 2005a) and the vector of controls conditional on which the interventions were randomized.

Column 1 of Table 14 simply focuses on the offered interest rate effect on repayment rate. The estimated coefficient on the interest rate variable is positive and statistically significant, indicating

\footnotetext{
${ }^{37}$ Education was predicted based the client's occupation (as reported in the Lender's records). The occupation variable was recoded to match that in the South African Living Standards Measurement Survey (LSMS). The LSMS was then used to predict years of education associated with a given occupation code.
} 
that those clients who took up a loan at higher interest rate are more likely to be late on their repayment. In contrast, columns 2 and 5 of Table 14 show that there is no statistically significant evidence of adverse selection on the psychological manipulations margin. In fact, all of the estimated coefficients on the treatment intensity variables on the full sample, while noisy, are negative.

There is thus a marked contrast between interest rate and psychological manipulation when regarded as two different instruments firms can use to increase profit. A hike in the interest rate will only increase profit if the pure price effect is not offset by the lower take-up rate and the adverse selection it induces. In contrast, the use of positive psychological features appears to have an unambiguous positive effect as it increases take-up (at a given interest rate) without adversely affecting the pool of borrowers.

In columns 3 and 4 , we contrast repayment behavior between male and female customers. As already shown in Karlan and Zinman (2005a), there appears to be more adverse selection on the interest rate margin among female customers. The point estimates in columns 3 and 4 also indicate some possible gender differences in adverse selection on the psychological margin, with some possible adverse selection for women but the opposite selection for men. However, standard errors are too large to draw any robust inference and in neither of the gender sub-samples can we reject the null hypothesis of no adverse selection.

\subsection{Crowd-Out and Crowd-In}

The final question we address is whether the psychological manipulations generate new borrowing or simply draw clients to the firm who would have borrowed elsewhere or at a different point in time. Alternatively, perhaps the marketing manipulations cause crowd-in by priming the individual more generally, encouraging borrowing after the deadline with this borrower or even encouraging borrowing with other lenders. To answer this question, the Lender collected for all individuals in the sample credit report information on their borrowing with other formal institutions over a six-month period following the mailing of the offer letter. The credit report aggregates loans taken from all other sources reporting to the credit bureau. Thus it presents a fairly accurate snap shot of formal sector borrowing but not of borrowing from the informal sector (such as money lenders, family or friends). We also collected for all individuals in the sample information on their borrowing from the Lender over a six-month period after the mailing of the offer letter (excluding any loan taken 
out in response to the offer letter). We then constructed based on this information two variables: whether the individual took up any loan from any of these sources, and how much in total the individual borrowed. We then regress these two variables on the two versions of the treatment intensity variable.

The results of this exercise are reported in Table 15. The dependent variable in the first 2 columns is total amount borrowed over that six-month period, excluding borrowing under this project from the Lender; the dependent variable in the last 2 columns is a dummy variable for any new borrowing over the six-month period, again excluding project borrowing from the Lender. As one can see from Table 15, we find no statistically significant evidence of a crowd-out or crowd-in effect, although the estimates are imprecise.

\section{Potential Reconciliation with Rational Choice Models}

Can our findings be reconciled with a rational choice model? We take in turn four possible lines of arguments towards such reconciliation.

One possible argument might be that while some psychological interventions indeed appear to affect demand, others have been shown to be ineffective. Should we regard this instability across manipulations as a sign of failure for a more behavioral model of choice? We think not. In fact, this variability in effectiveness is central to the psychological literature, which places great emphasis on contextual specificity. ${ }^{38}$ In addition, as we saw in Table 12, context specificity does not appear to be restricted to the psychological model but may also be intrinsic to the rational choice model. In that table, we showed significant interactions between the psychological variables and the price variable. Put another way, had we run a pure interest rate experiment to measure the elasticity of demand, our findings in Table 12 show that the results might have differed substantially based on numerous features of the offer letter.

Another attempt at reconciliation would be to argue that the clients in our experiment were relatively indifferent about whether to get a loan or not. Under this view, some of the psychological interventions have such a large effect only because they "push in" people who stand on the margin

\footnotetext{
${ }^{38}$ Contextual specificity could also help to explain why prior field studies, which typically focus on one single manipulation, themselves differ in whether they uncover psychological effects or not. Because our study examines numerous psychological manipulations at once, it makes the variability in effectiveness more transparent.
} 
of whether or not to take a loan. This view, however, is inconsistent with our price sensitivity benchmarking exercise. If clients are rational and indifferent between taking a loan and not, small variation in prices ought to have very large effects on take-up. ${ }^{39}$ This in turn would mute the relative importance of the psychological interventions. In other words, by scaling the psychological effects in interest rate terms, we adjust for the intensity of preference in price terms.

Another line of argument is that perhaps some of the psychological interventions we have performed provide informative signals to the client about the offer. Obviously, any such signaling could not be about the interest rate (as this information is already directly available on the offer letter and a rational customer has all the needed information to compare this rate to the market rate). But maybe the psychological interventions provide informative signals about the lender. For example, a female photo on the offer letter may signal a friendlier lender. Or the addition of a promotional giveaway may signal a lower quality or "shadier" lender. Such signals may rationally enter into customers' cost-benefit calculation about the attractiveness of the offer. There are at least four different reasons why we find such an informative signaling explanation weak. First, it is important to remember who the customers in our experiment were. All these customers have interacted with the Lender in the past, some more frequently than others. It is not clear how much information about the Lender these customers could get from the offer letter that they have not already obtained through their direct interaction with that Lender. Also, as we discussed earlier, we find no evidence of greater past experience (measured in terms of number of past loans) dampening the sensitivity of demand to the psychological interventions. Second, even if customers are only partially informed about the Lender and the offer letter is providing an informative signal, one is left with a magnitude puzzle. How much can rationally be learned about the Lender from the offer letter to justify the large magnitude effects we have uncovered? Third, it is not clear why any of the manipulations we have performed on the offer letter could qualify as signals that a rational customer should draw information from. Because these manipulations are virtually costless to the Lender, it seems unreasonable that the Lender's type could rationally be signaled through them. For example, if customers understand that it is costless for any lender to include or not a promotional lottery in their offer, why would they rationally update their prior about a lender's type based on the inclusion or not of such a lottery? Finally, the priming call was not even from

\footnotetext{
${ }^{39}$ Unless clients are indifferent about everything altogether, which would be a rather vacuous model.
} 
the Lender, but rather from a "consumer market research firm."

A different confounding factor in interpreting our results is the specificity of the South African context. How comparable would we expect the results of a similar experiment to be in another country? It is impossible to tell. We can only argue for the fact that the individuals in our sample are experienced users in this credit market and are familiar with the product and terms. Of course, even among these experienced customers, one might still argue that perhaps they had only limited exposure to advertising in the past and that greater exposure to advertising may reduce the response to the psychological manipulations. While there may indeed be very large learning effects on this front, it is important to note that advertising is very common in South Africa, though direct mail solicitations are nowhere near as common as in the United States. Remember also that we find no evidence of weaker sensitivity to the interventions among the most educated or higher income customers in our sample, who are arguably likely to have had more exposure to other forms of advertising. The argument that our results are specific only to South Africa is further weakened by the fact that most psychological manipulations we employed were first documented in the west, predominantly on American campuses and among American consumers. More indirectly, the hypothesis that learning reduces these behavioral responses contrasts quite sharply with the very large advertising outlays made my most companies, and especially those operating in the consumer goods and services sectors.

\section{Conclusion}

In contrast to the neoclassical theory, which assumes stable values and preferences, behavioral research has suggested that people often do not have well-established values, and that preferences are actually constructed - not merely revealed - during their elicitation. The findings in this paper lend themselves to such a constructive interpretation. Decisions, according to this analysis, are often reached by focusing on various features of the decision context that elicit the selection of one option over another. Different frames, contexts, and elicitation details highlight different aspects of the options and bring forth different reactions and considerations, often unconscious, that influence decision.

In the context of a field experiment in the consumer credit market in South Africa, we have em- 
pirically argued that a firm can exploit consumers' psychological biases, thereby increasing demand without lowering prices. Three key features of our findings are worth stressing in these concluding remarks. First, while several of the psychological manipulations we attempted affected demand, several did not. This suggests, as already noted and often discussed in the psychological literature, that psychological effects are very context sensitive and may require experimentation to pin down. To a certain degree, this is not unlike the experimentation firms may have to engage in to pin down the "optimal price." Second, the magnitude of these psychological effects is large, with each statistically significant intervention equivalent to drops in the monthly interest rate ranging from 1 percentage point (most often) to sometimes as much as 4 percentage points.

Finally, our combined findings regarding the absence of adverse selection on the psychological margin, the weakened price sensitivity associated with the psychologically more loaded offer and (more tentatively) the apparent lack of a crowd-out effect suggest that psychology may impact the market equilibrium. By competing on these psychological factors, firms may be able to raise demand without suffering from adverse selection, all the while dulling the incentives for price competition.

While the implications of these findings are directly relevant to the marketing of consumer goods and services in the for-profit sector, we believe that many of the insights gained in this paper are also relevant for the design of socially oriented programs. Greater care in recognizing human cognitive limitations (such as a tendency to forget or to postpone decisions in the face of richer option sets) may have first-order effects on program participation decisions. For example, such cognitive proclivities may have to be more fully taken into account in the design of health care or retirement savings plan choices. The findings of this paper suggest that, through increased focus on the marketing of their programs, governmental agencies may achieve broader participation without having to solely rely on greater financial incentives. The framing of any initiative, program or product can be just as important as the actual terms of the offer. This implies that attention should be paid to understanding these effects in the formation of public policies (see Thaler and Sunstein, 2003).

As a whole, our findings suggest that standard economic models may be missing some important drivers of choice. But our findings also clearly indicate that the incorporation of these drivers into our models will not be a simple task. Instead, it will require a much deeper understanding of the specific contexts in which a particular psychological driver is likely to be relevant and the specific 
contexts in which it is not. The economic magnitude of our findings, however, suggests that the development of richer models may be necessary in order to reach a more accurate description of economic behavior. 


\section{References}

Ameriks, John, Andrew Caplin and John Leahy, 2003, "Wealth Accumulation and the Propensity to Plan," Quarterly Journal of Economics, 118, 1007-1047.

Ashraf, Nava, Dean Karlan and Wesley Yin, 2006 (forthcoming), "Tying Odysseus to the Mast: Evidence from a Commitment Savings Product in the Philippines," Quarterly Journal of Economics.

Ausubel, Lawrence, 1999, "Adverse Selection in the Credit Card Market," University of Maryland Working Paper.

Bertrand, Marianne, Dean Karlan, Sendhil Mullainathan, Eldar Shafir and Jonathan Zinman, 2005, "Do Deadlines Spur Behavior? A Field Experiment in Consumer Credit," in progress.

Camerer, Colin F. George Loewenstein and Matthew Rabin, 2003, Advances in Behavioral Economics, Princeton, NJ: Princeton University Press.

Chan, Sewin and Ann Huff Stevens, 2004, "What You Don't Know Can't Help You: Pension Knowledge and Retirement Decision Making," Working Paper.

Cialdini, Robert B., 2001, Influence: Science and Practice (4th Ed.), Allyn and Bacon.

Day, George S., 2003, "Creating a Superior Customer-Relating Capability," MIT Sloan Management Review, 44.

Dhar, Sanjay K. and Hoch, Stephen J. "Price Discrimination Using In-Store Merchandising." Journal of Marketing, 1996, 60(1), pp. 17-30.

Ding, Min, Grewal, Rajdeep and Liechty, John. "Incentive-Aligned Conjoint Analysis." Journal of Marketing Researc, 2005, 42, pp. 67-82.

Dreze, Xavier, Stephen J. Hoch and Mary E. Purk, 1994, "Shelf Management and Space Elasticity, Journal of Retailing, 70(4), 301.

Evans, Franklin B., 1963, "Selling as a Dyadic Relationship," American Behavioral Scientist, 6, 76-79.

Fitzsimons, Gavan J., and Baba Shiv, 2001, "Nonconscious and Contaminative Effects of Hypothetical Questions on Subsequent Decision Making," Journal of Consumer Research, 28, 224-238.

Ganzach, Yoav and Nili Karsahi, 1995, "Message Framing and Buying Behavior: A Field Experiment, Journal of Business Research, vol. 32, issue 1, 11-17.

Green, Paul E., Abba M Krieger, and Yoram Wind, 2001, "Thirty years of conjoint analysis: Reflections and prospects, Interfaces Linthicum, vol. 31, issue 3, part 2, p. S56-S73.

Greenwald, A. G., Carnot, C. G., Beach, R., and Young, B., 1987, "Increasing Voting Behavior by Asking People if They Expect to Vote," Journal of Applied Psychology, 72, 315-318.

Harrison, Glenn and List, John, 2004, "Field Experiments," Journal of Economic Literature, XLII, 1009-1055.

Huber, J., Payne, J., and Puto, C., 1982, "Adding Asymmetrically Dominated Alternatives: Viola- 
tions of Regularity and the Similarity Hypothesis," Journal of Consumer Research, 9, 90-98. Iyengar, Sheena, Jiang, Wei and Huberman, Gur, 2003, "How Much Choice is Too Much? Contributions to 401(k) Retirement Plans," Pension Research Council Working Paper 2003-10.

Iyengar, Sheena and Wei Jiang, 2003, "How More Choices are Demotivating: Impact of More Options on 401(k) Investment," Working Paper.

Iyengar, Sheena and Mark Lepper, 2000, "When Choice is Demotivating: Can One Desire Too Much of a Good Thing?" Journal of Personality and Social Psychology, 79, 995-1006.

Kahneman, Daniel and Amos Tversky, 1979, "Prospect Theory: An Analysis of Decision Under Risk," Econometrica, 47,263-291.

Kahneman, Daniel and Amos Tversky, 2000, Choices, Values, and Frames, Cambridge University Press.

Karlan, Dean and Jonathan Zinman, 2005a, "Observing Unobservables: Identifying Information Asymmetries with a Consumer Credit Field Experiment," working paper.

Karlan, Dean and Jonathan Zinman, 2005b, "Elasticities of Demand for Consumer Credit," working paper.

Laibson, David, 2001, "A Cue-Theory of Consumption," Quarterly Journal of Economics, 116, 81-119.

Levitt, Steven D. and John A. List, 2005, "What Do Laboratory Experiments Tell Us About the Real World?" University of Chicago Working Paper.

Landry, Craig and Andreas Lange, John List, Michael Price and Nicholas Rupp, "Towards an Understanding of the Economics of Charity: Evidence from a Field Experiment", 2005, working paper.

Lord, Charles G., 1997, Social Psychology, Holt, Rinehart, and Winston.

Mandel, Naomi and Eric J. Johnson, 2002, "When Web Pages Influence Choice: Effects of Visual Primes on Experts and Novices," Journal of Consumer Research, 29, 235-45.

Mobius, Markus and Rosenblat, Tanya, 2005, "Why Beauty Matters," American Economic Review, (forthcoming).

Morwitz, Vicki G., Eric J. Johnson, and David Schmittlein, 1993, "Does Measuring Intent Change Behavior?" Journal of Consumer Research, 20, 46-61.

Odean, Terrence, 1998, "Are Investors Reluctant to Realize Their Losses?" Journal of Finance, $53,1775-1798$.

Porteous, David, 2003, "Is Cinderella Finally Coming to the Ball: Microfinance in Broad Perspective,"http://www.finmark.org.za/researchmaterial/presentations/2003/Cinderella2.pdf.

Redelmeier, Donald A., and Eldar Shafir, 1995, "Medical Decision Making in Situations that Offer Multiple Alternatives," Journal of the American Medical Association, 273, 302-305.

Ross, L.D. and Nisbett, R.E., 1991, The Person and the Situation: Perspectives of Social Psychology, New York: McGraw-Hill. 
Shafir, Eldar, Itamar Simonson and Amos Tversky, 1993, "Reason-Based Choice," Cognition, 49, 11-36.

Sherman, S.J., 1980, "On the Self-Erasing Nature of Errors of Prediction." Journal of Personality and Social Psychology, 39, 211-221.

Simester, Duncan, 2004, "Finally, Market Research You Can Use," Harvard Business Review, 82, $20-21$.

Simon, Herbert, 1955, "A Behavioral Model of Rational Choice," Quarterly Journal of Economics, 69, 99-118.

Simonson, Itamar, Ziv Carmon and Sue O'Curry, 1994, "Experimental Evidence on the Negative Effect of Product Features and Sales Promotions on Brand Choice," Marketing Science, 13, 23-40.

Slovic, Paul, Melissa Finucane, Ellen Peters, and Donald G. MacGregor, 2002, "The Affect Heuristic," in T. Gilovich, D. Griffin, \& D. Kahneman, (eds.), Heuristics and Biases: The Psychology of Intuitive Judgment, Cambridge University Press, 397-420.

Smith, Jennifer K., Alan S. Gerber, and Anton Orlich, 2003, "Self-Prophecy Effects and Voter Turnout: An Experimental Replication," Political Psychology, 24, 593-604.

Thaler, Richard H., 1990, "Saving, Fungibility, and Mental Accounts," Journal of Economic Perspectives, 4, 193-205.

Thaler, Richard H., and Shlomo Benartzi, 2004, "Save More Tomorrow: Using Behavioral Economics to Increase Employee Saving," Journal of Political Economy, 112, S164-S187.

Thaler, Richard H. and Cass R. Sunstein, "Libertarian Paternalism," American Economic Review, 2003, 93, 175-79.

Tversky, Amos and Kahneman, Daniel, 1991, "Loss Aversion in Riskless Choice: A Reference Dependent Model," Quarterly Journal of Economics, November, 1039-1061.

Wansink, Brian, Robert J. Kent, and Stephen J. Hoch, 1998, "An Anchoring and Adjustment Model of Purchase Quantity Decisions," Journal of Marketing Research, 35 (February), 71-81. 
Table 1

Summary of Customers Characteristics ${ }^{a}$

(1)

\section{Sample: All}

Male

Black

Coloured

Indian

White

Low risk

Medium risk

High risk

Months since

last loan

Previous number

of loans

Gross monthly

income (rands)

Predicted education

(years)

Sample
(2)

(3)

(4)

(5)

\section{"High attention" customer}

0.520

(0.50)

0.870

(0.34)

0.032

(0.17)

0.026

(0.16)

0.072

(0.26)

0.419

(0.49)

0.309

(0.46)

0.272

(0.44)

3.936

(2.28)

5.863

(4.10)

3756

(34511)

6.934

(3.25)

17108

\section{"Low attention" customer}

0.525

(0.50)

0.840

(0.37)

0.036

(0.19)

0.034

$(0.18)$

0.089

$(0.29)$

0.000

$(0.02)$

0.006

(0.08)

0.994

(0.08)

13.500

(6.02)

3.325

(3.30)

3255

(2208)

6.810

(3.25)

36086

${ }^{a}$ Notes:

1. "All" is the entire set of customers that were mailed the experimental loan offer, excluding those for which the offer letter was returned to the Lender. "Customers who took up" is the sub-sample of customers that took up a loan by the letter-specific stated deadline; "Customers who did not take up" is the remaining sub-sample. "High attention customers" is the sub-sample of customers that have borrowed at least twice from the Lender in the past and at least once in the last eight months; "low attention customers" is the remaining sub-sample.

2. "High risk," "medium risk," and "low risk" are categories constructed by the Lender based on internal records on customers' credit history (see text for details). "Predicted education" is computed based on the customers occupation (as recorded by the Lender). This occupation variable was recoded to match that in the South African Living Standards Measurement Survey (LSMS); the LSMS was then used to predict the years of education associated with particular occupations.

3. Reported in the table are means and standard deviations (in parentheses). 
Table 2

Summary of Randomized Interventions ${ }^{a}$

(1)

$(2)$

(3)

(4)

$(5)$

Sample: All Customers who did Customers who "High attention" not take up

took up

0.401

$(0.49)$

0.599

(0.49)

7.233

(2.31)

0.349

(0.48)

0.200

(0.40)

0.408

(0.49)

0.206

(0.40)

0.476

(0.50)

0.071

(0.26)

0.122

(0.33)

0.125

(0.33)

0.411

(0.49)

0.383

(0.49)

0.531

(0.50)

0.388

(0.49)

0.246

(0.43)

0.005

(0.07) customer

0.398

(0.49)

0.602

(0.49)

6.970

(2.11)

0.250

$(0.43)$

0.202

(0.40)

0.397

(0.49)

0.198

(0.40)

0.488

(0.50)

0.072

(0.26)

0.123

$(0.33)$

0.120

(0.32)

0.398

(0.49)

0.404

(0.49)

0.537

(0.50)

0.403

(0.49)

0.250

(0.43)

0.003

(0.05)

17108

\section{"Low attention"} customer

0.393

(0.49)

0.607

(0.49)

8.384

(2.43)

0.518

(0.50)

0.199

(0.40)

0.403

(0.49)

0.204

(0.40)

0.472

(0.50)

0.071

(0.26)

0.126

(0.33)

0.127

(0.33)

0.399

(0.49)

0.397

(0.49)

0.533

(0.50)

0.400

(0.49)

0.251

(0.43)

0.003

(0.05)

36086

\footnotetext{
${ }^{a}$ Notes:See next page.
} 
Notes:

1. "All" is the entire set of customers that were mailed the experimental loan offer, excluding those for which the offer letter was returned to the Lender. "Customers who took up" is the sub-sample of customers that took up a loan by the letter-specific stated deadline; "Customers who did not take up" is the remaining sub-sample. "High attention customers" is the sub-sample of customers that have borrowed at least twice from the Lender in the past and at least once in the last eight months; "low attention customers" is the remaining sub-sample.

2. See text for a detailed description of each of the interventions.

3. Reported in the table are means and standard deviations (in parentheses). 
Table 3 Effect of Simplicity of Offer Description on Take-Up ${ }^{a}$

\begin{tabular}{|c|c|c|c|}
\hline $\begin{array}{c}\text { Dependent Var } \\
\text { Sample: }\end{array}$ & $\begin{array}{l}\text { able: Tal } \\
\text { All }\end{array}$ & $\begin{array}{l}\text {-Up Dummy } \\
\text { High } \\
\text { attention }\end{array}$ & $\begin{array}{c}\text { Low } \\
\text { attention }\end{array}$ \\
\hline & (1) & (2) & (3) \\
\hline Small option table & $\begin{array}{c}0.603 \\
(0.239)\end{array}$ & $\begin{array}{l}1.146 \\
(0.674)\end{array}$ & $\begin{array}{c}0.407 \\
(0.219)\end{array}$ \\
\hline$\Delta$ interest rate equivalent & {$[2.337]$} & {$[3.570]$} & {$[1.887]$} \\
\hline Interest rate & $\begin{array}{l}-0.258 \\
(0.049)\end{array}$ & $\begin{array}{l}-0.321 \\
(0.145)\end{array}$ & $\begin{array}{l}-0.215 \\
(0.044)\end{array}$ \\
\hline Risk category F.E.? & yes & yes & yes \\
\hline Experimental wave F.E.? & yes & yes & yes \\
\hline Sample size & 53194 & 17108 & 36086 \\
\hline
\end{tabular}

${ }^{a}$ Notes:

1. "All" is the entire set of customers that were mailed the experimental loan offer, excluding those for which the offer letter was returned to the Lender. "High attention" is the subsample of customers that have borrowed at least twice from the Lender in the past and at least once in the last eight months; "low attention" is the remaining sub-sample.

2. The dependent variable is a dummy variable that equals 1 if the customer took up at least one loan by the stated deadline on the offer letter, 0 otherwise.

3. "Small option table" is a dummy variable that equals 1 if the offer letter displayed only one example of a loan, 0 otherwise. See text for details.

4. "Risk category F.E." are fixed effects for the 3 risk categories among borrowers (high, medium, low). "Experimental wave F.E." are fixed effects for the 2 experimental waves (September and October). See text for details.

5. Each column corresponds to the estimation of a probit model. Reported in the table are marginal effects. For each column, " $\Delta$ interest rate equivalent" is computed as the ratio of the estimated effect of the psychological intervention on take-up to the estimated effect of the interest rate on take-up. 


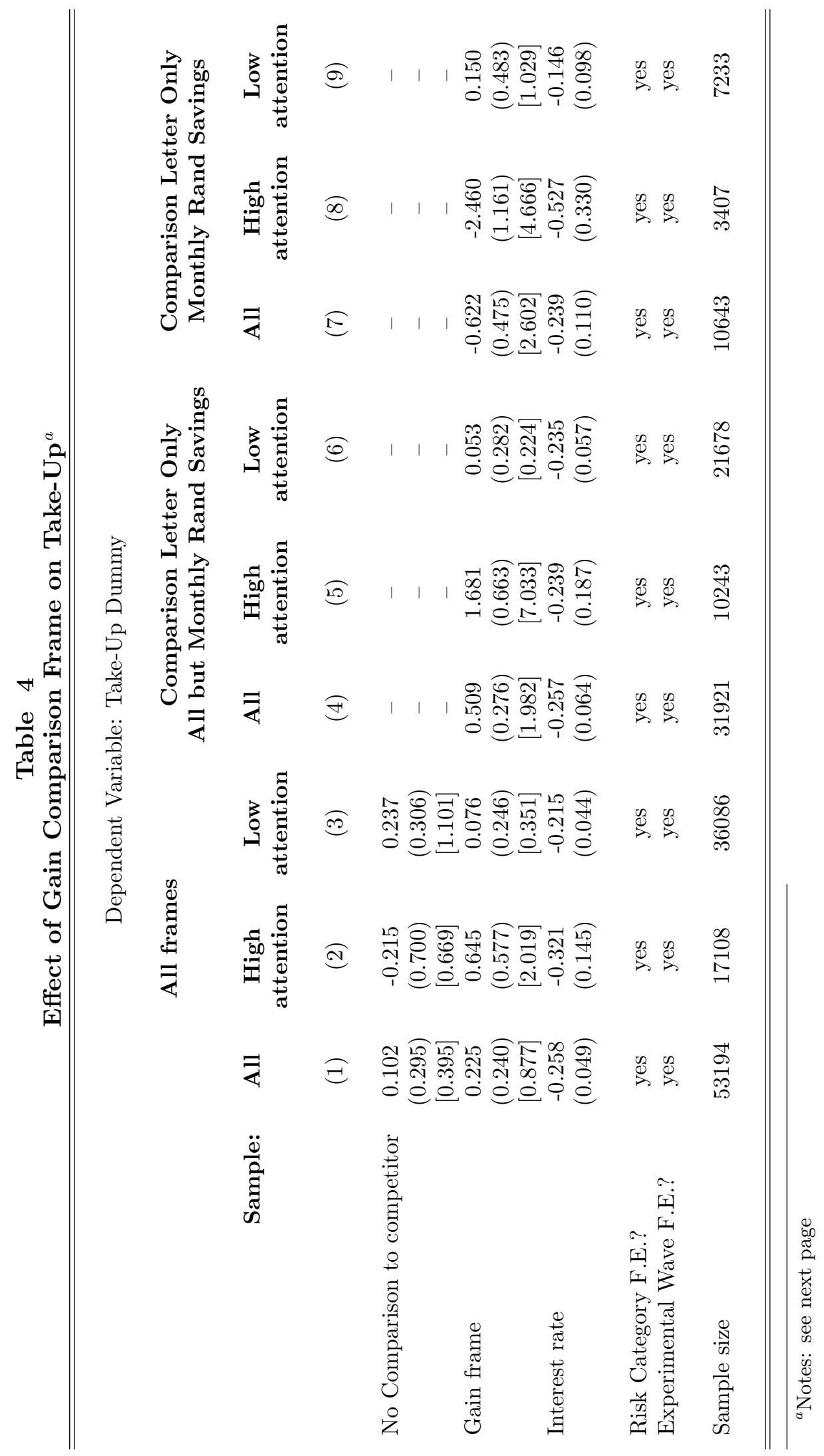




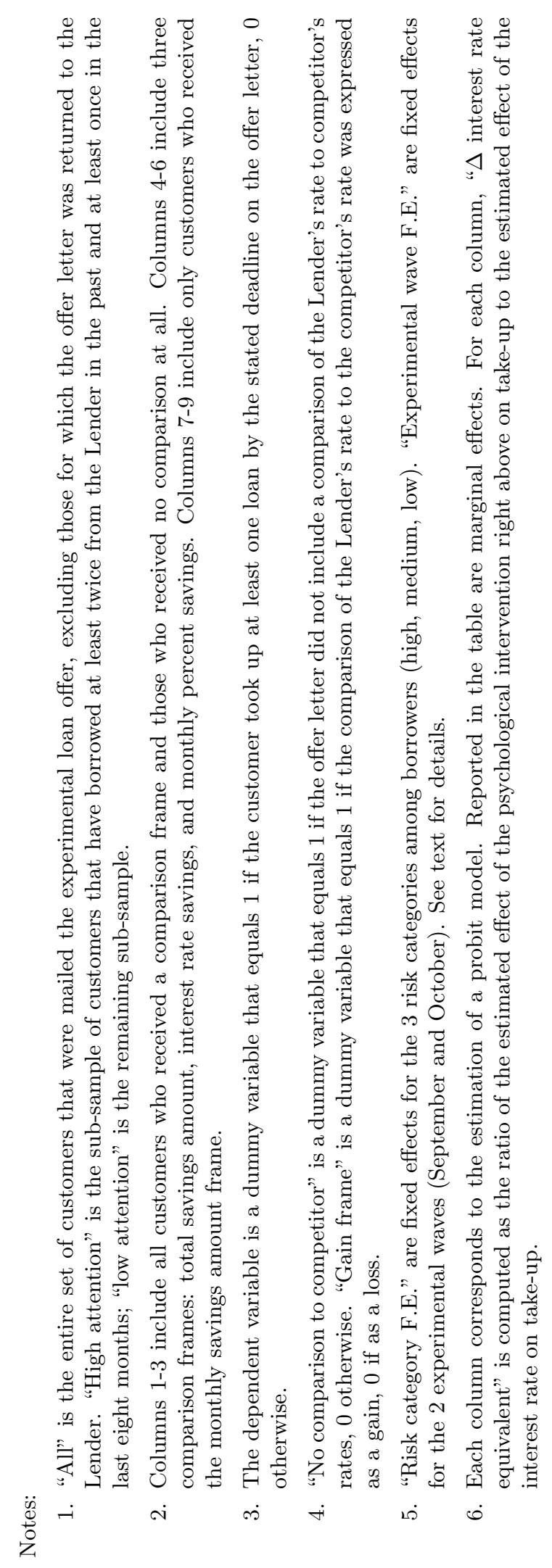




\title{
Table 5 \\ Effect of Race on Photo on Take-Up ${ }^{a}$
}

\author{
Dependent Variable: Take-Up Dummy \\ Sample: All High Low \\ attention attention
}

\begin{tabular}{lccc} 
No photo & 0.049 & 0.809 & -0.237 \\
& $(0.414)$ & $(1.036)$ & $(0.403)$ \\
Black photo & {$[0.191]$} & {$[3.149]$} & {$[0.924]$} \\
& 0.239 & 0.745 & -0.025 \\
& $(0.483)$ & $(1.219)$ & $(0.474)$ \\
Coloured photo & {$[0.931]$} & {$[2.898]$} & {$[0.098]$} \\
& -0.179 & 0.743 & -0.568 \\
& $(0.517)$ & $(1.325)$ & $(0.487)$ \\
Indian photo & {$[0.695]$} & {$[2.891]$} & {$[2.209]$} \\
& -0.212 & 0.872 & -0.611 \\
& $(0.445)$ & $(1.142)$ & $(0.420)$ \\
White photo & {$[0.825]$} & {$[3.393]$} & {$[2.376]$} \\
& omitted & omitted & omitted \\
Race match & & & \\
& -0.391 & 0.289 & -0.614 \\
Interest rate & $(0.437)$ & $(1.103)$ & $(0.432)$ \\
& {$[1.520]$} & {$[1.123]$} & {$[2.388]$} \\
& -0.257 & -0.322 & -0.213 \\
& $(0.049)$ & $(0.145)$ & $(0.044)$ \\
Risk category F.E.? & 53194 & 17108 & 36086 \\
Experimental wave F.E.? & & & \\
Race F.E.? & yes & yes & yes \\
Sample size & yes & yes & yes \\
& & & \\
& 53194 & 17108 & 36086 \\
\hline \hline
\end{tabular}

${ }^{a}$ Notes:

1. "All" is the entire set of customers that were mailed the experimental loan offer, excluding those for which the offer letter was returned to the Lender. "High attention" is the subsample of customers that have borrowed at least twice from the Lender in the past and at least once in the last eight months; "low attention" is the remaining sub-sample.

2. The dependent variable is a dummy variable that equals 1 if the customer took up at least one loan by the stated deadline on the offer letter, 0 otherwise.

3. "Black photo" is a dummy variable that equals 1 if the offer letter includes the photo of a black individual, 0 otherwise. "Coloured photo," "Indian photo," and "White photo," are similarly defined. "Race match" is a dummy variable that equals 1 if the race on the photo matches the race of the customer, 0 otherwise. "No photo" is a dummy variable that equals 1 if no photo was displayed on the offer letter, 0 otherwise. See text for details.

4. "Risk category F.E." are fixed effects for the 3 risk categories among borrowers (high, medium, low). "Experimental wave F.E." are fixed effects for the 2 experimental waves (September and October). See text for details. "Race F.E." are fixed effects for the race of the customer.

5. Each column corresponds to the estimation of a probit model. Reported in the table are marginal effects. For each column, reported under brackets is the ratio of the estimated effect of the psychological intervention right above on take-up to the estimated effect of the interest rate on take-up. 
Table 6

Effect of Gender on Photo on Take-Up ${ }^{a}$

\begin{tabular}{|c|c|c|c|c|c|c|}
\hline \multirow{3}{*}{$\begin{array}{r}\text { Panel A: Both Genders } \\
\text { Sample: }\end{array}$} & \multicolumn{6}{|c|}{ Dependent Variable: Take-Up Dummy } \\
\hline & \multicolumn{2}{|c|}{ Full } & \multicolumn{2}{|c|}{$\begin{array}{c}\text { High } \\
\text { attention }\end{array}$} & \multicolumn{2}{|c|}{$\begin{array}{l}\text { Low } \\
\text { attention }\end{array}$} \\
\hline & (1) & $(2)$ & $(3)$ & $(4)$ & $(5)$ & $(6)$ \\
\hline Opposite gender & $\begin{array}{c}0.346 \\
(0.241) \\
{[1.341]}\end{array}$ & & $\begin{array}{l}0.765 \\
(0.577) \\
{[2.368]}\end{array}$ & & $\begin{array}{c}0.187 \\
(0.248) \\
{[0.869]}\end{array}$ & \\
\hline Female photo & & $\begin{array}{l}0.571 \\
(0.243) \\
{[2.223]}\end{array}$ & & $\begin{array}{l}0.786 \\
(0.577) \\
{[2.456]}\end{array}$ & & $\begin{array}{l}0.483 \\
(0.251) \\
{[2.245]}\end{array}$ \\
\hline No photo & $\begin{array}{c}0.460 \\
(0.300)\end{array}$ & $\begin{array}{c}0.579 \\
(0.303)\end{array}$ & $\begin{array}{c}0.434 \\
(0.715)\end{array}$ & $\begin{array}{c}0.443 \\
(0.714)\end{array}$ & $\begin{array}{c}0.479 \\
(0.310)\end{array}$ & $\begin{array}{c}0.639 \\
(0.316)\end{array}$ \\
\hline Interest rate & $\begin{array}{l}{[1.785]} \\
-0.258 \\
(0.049)\end{array}$ & $\begin{array}{l}{[2.252]} \\
-0.257 \\
(0.049)\end{array}$ & $\begin{array}{l}{[1.345]} \\
-0.323 \\
(0.145)\end{array}$ & $\begin{array}{l}{[1.384]} \\
-0.320 \\
(0.145)\end{array}$ & $\begin{array}{l}{[2.225]} \\
-0.215 \\
(0.044)\end{array}$ & $\begin{array}{l}{[2.975]} \\
-0.215 \\
(0.044)\end{array}$ \\
\hline \multirow{3}{*}{$\begin{array}{l}\text { Customer gender? } \\
\text { Risk category F.E.? } \\
\text { Experimental wave F.E.? }\end{array}$} & yes & yes & yes & yes & yes & yes \\
\hline & yes & yes & yes & yes & yes & yes \\
\hline & yes & yes & yes & yes & yes & yes \\
\hline Sample size & 53194 & 53194 & 17108 & 17108 & 36086 & 36086 \\
\hline \multirow{2}{*}{$\begin{array}{l}\text { Panel B: By Gender } \\
\text { Sample: }\end{array}$} & \multicolumn{3}{|c|}{ Male Customers } & \multicolumn{3}{|c|}{ Female Customers } \\
\hline & All & $\begin{array}{c}\text { High } \\
\text { attention }\end{array}$ & $\begin{array}{c}\text { Low } \\
\text { attention }\end{array}$ & All & $\begin{array}{c}\text { High } \\
\text { attention }\end{array}$ & $\begin{array}{c}\text { Low } \\
\text { attention }\end{array}$ \\
\hline \multirow[t]{2}{*}{ Opposite gender } & $\begin{array}{c}0.871 \\
(0.332)\end{array}$ & $\begin{array}{c}1.486 \\
(0.794)\end{array}$ & $\begin{array}{c}0.635 \\
(0.343)\end{array}$ & $\begin{array}{c}-0.231 \\
(0.351)\end{array}$ & $\begin{array}{c}-0.009 \\
(0.840)\end{array}$ & $\begin{array}{l}-0.310 \\
(0.359)\end{array}$ \\
\hline & {$[4.521]$} & {$[5.515]$} & {$[4.080]$} & {$[0.703]$} & {$[0.024]$} & {$[1.105]$} \\
\hline \multirow[t]{3}{*}{ No photo } & 0.580 & 0.653 & 0.573 & 0.336 & 0.174 & 0.383 \\
\hline & $(0.414)$ & $(0.983)$ & $(0.432)$ & $(0.435)$ & $(1.040)$ & $(0.444)$ \\
\hline & {$[3.011]$} & {$[2.425]$} & {$[3.684]$} & {$[1.021]$} & {$[0.454]$} & {$[1.367]$} \\
\hline \multirow[t]{2}{*}{ Interest rate } & -0.193 & -0.269 & -0.156 & -0.329 & -0.383 & -0.280 \\
\hline & $(0.067)$ & $(0.199)$ & $(0.061)$ & $(0.072)$ & $(0.212)$ & $(0.064)$ \\
\hline Risk category F.E.? & yes & yes & yes & yes & yes & yes \\
\hline Experimental wave F.E.? & yes & yes & yes & yes & yes & yes \\
\hline Sample size & 27848 & 8903 & 18945 & 25346 & 8205 & 17141 \\
\hline
\end{tabular}

\footnotetext{
${ }^{a}$ Notes: See next page.
} 
Notes:

1. "All" is the entire set of customers that were mailed the experimental loan offer, excluding those for which the offer letter was returned to the Lender. "High attention" is the sub-sample of customers that have borrowed at least twice from the Lender in the past and at least once in the last eight months; "low attention" is the remaining sub-sample. These samples are broken down by gender in Panel B.

2. The dependent variable is a dummy variable that equals 1 if the customer took up at least one loan by the stated deadline on the offer letter, 0 otherwise.

3. "Female photo" is a dummy variable that equals 1 if the offer letter includes the photo of a woman, 0 otherwise. "Opposite gender" is a dummy variable that equals 1 if the gender on the photo is the opposite of the customers gender, 0 otherwise. "No photo" is a dummy variable that equals 1 if no photo was displayed on the offer letter, 0 otherwise. See text for details.

4. "Risk category F.E." are fixed effects for the 3 risk categories among borrowers (high, medium, low). "Experimental wave F.E." are fixed effects for the 2 experimental waves (September and October). See text for details. "Customer gender" is a dummy variable for the gender of the customer.

5. Each column corresponds to the estimation of a probit model. Reported in the table are marginal effects. For each column, reported under brackets is the ratio of the estimated effect of the psychological intervention right above on take-up to the estimated effect of the interest rate on take-up. 
Table 7

Effect of Promotional Lottery on Take-Up ${ }^{a}$

\begin{tabular}{lccc}
\hline \hline \multicolumn{4}{c}{ Dependent Variable: Take-Up Dummy } \\
Sample: & All & $\begin{array}{c}\text { High } \\
\text { attention }\end{array}$ & $\begin{array}{c}\text { Low } \\
\text { attention }\end{array}$ \\
& & & \\
& $(1)$ & $(2)$ & $(3)$ \\
& & & \\
Promotional lottery & -0.133 & -1.162 & 0.290 \\
& $(0.245)$ & $(0.579)$ & $(0.256)$ \\
& {$[0.517]$} & {$[3.602]$} & {$[1.349]$} \\
Interest rate & -0.258 & -0.323 & -0.215 \\
& $(0.049)$ & $(0.145)$ & $(0.044)$ \\
Risk category F.E.? & yes & yes & yes \\
Experimental wave F.E.? & yes & yes & yes \\
& & & \\
Sample size & 53194 & 17108 & 36086 \\
& & & \\
\hline \hline
\end{tabular}

${ }^{a}$ Notes:

1. "All" is the entire set of customers that were mailed the experimental loan offer, excluding those for which the offer letter was returned to the Lender. "High attention" is the subsample of customers that have borrowed at least twice from the Lender in the past and at least once in the last eight months; "low attention" is the remaining sub-sample.

2. The dependent variable is a dummy variable that equals 1 if the customer took up at least one loan by the stated deadline on the offer letter, 0 otherwise.

3. "Promotional lottery" is a dummy variable that equals 1 if the offer letter mentions a promotional lottery, 0 otherwise. See text for details.

4. "Risk category F.E." are fixed effects for the 3 risk categories among borrowers (high, medium, low). "Experimental wave F.E." are fixed effects for the 2 experimental waves (September and October). See text for details.

5. Each column corresponds to the estimation of a probit model. Reported in the table are marginal effects. For each column, reported under brackets is the ratio of the estimated effect of the psychological intervention on take-up to the estimated effect of the interest rate on take-up. 
Table 8

Effect of Suggestion Phone Call on Take-Up ${ }^{a}$

\begin{tabular}{|c|c|c|c|c|c|c|c|c|c|}
\hline \multicolumn{10}{|c|}{ Dependent Variable: Take-Up Dummy } \\
\hline \multirow[t]{2}{*}{ Sample: } & \multicolumn{3}{|c|}{ All } & \multicolumn{3}{|c|}{$\begin{array}{c}\text { High } \\
\text { attention }\end{array}$} & \multicolumn{3}{|c|}{$\begin{array}{c}\text { Low } \\
\text { attention }\end{array}$} \\
\hline & $(1)$ & $(2)$ & (3) & $(4)$ & $(5)$ & (6) & (7) & (8) & (9) \\
\hline Specification & Probit & Probit & IV & Probit & Probit & IV & Probit & Probit & IV \\
\hline $\begin{array}{l}\text { Suggestion call } \\
\text { (treated) }\end{array}$ & $\begin{array}{c}5.00 \\
(2.12) \\
{[21.50]}\end{array}$ & $\begin{array}{c}5.22 \\
(2.12) \\
{[21.42]}\end{array}$ & $\begin{array}{c}7.55 \\
(3.54) \\
{[30.89]}\end{array}$ & $\begin{array}{c}6.41 \\
(4.70) \\
{[14.61]}\end{array}$ & $\begin{array}{c}6.56 \\
(4.74) \\
{[14.06]}\end{array}$ & $\begin{array}{c}9.03 \\
(7.71) \\
{[19.36]}\end{array}$ & $\begin{array}{c}4.06 \\
(2.14) \\
{[23.06]}\end{array}$ & $\begin{array}{c}4.42 \\
(2.13) \\
{[24.42]}\end{array}$ & $\begin{array}{c}6.47 \\
(3.60) \\
{[35.72]}\end{array}$ \\
\hline Interest rate & $\begin{array}{l}-0.23 \\
(0.07)\end{array}$ & $\begin{array}{l}-0.24 \\
(0.07)\end{array}$ & $\begin{array}{l}-0.27 \\
(0.23)\end{array}$ & $\begin{array}{l}-0.44 \\
(0.19)\end{array}$ & $\begin{array}{l}-0.47 \\
(0.19)\end{array}$ & $\begin{array}{l}-0.47 \\
(0.19)\end{array}$ & $\begin{array}{l}-0.18 \\
(0.06)\end{array}$ & $\begin{array}{l}-0.18 \\
(0.06)\end{array}$ & $\begin{array}{l}-0.18 \\
(0.06)\end{array}$ \\
\hline Customer characs.? & no & yes & yes & no & yes & yes & no & yes & yes \\
\hline Experimental wave F.E.? & yes & yes & yes & yes & yes & yes & yes & yes & yes \\
\hline Risk category F.E.? & yes & yes & yes & yes & yes & yes & yes & yes & yes \\
\hline Sample size & 28713 & 28353 & 28353 & 9254 & 9171 & 9171 & 19459 & 19182 & 19182 \\
\hline
\end{tabular}

${ }^{a}$ Notes:

1. "All is the entire set of customers that were mailed the experimental loan offer in the second experimental wave, excluding those for which the offer letter was returned to the Lender. "High attention" is the sub-sample of customers that have borrowed at least twice from the Lender in the past and at least once in the last eight months; "low attention" is the remaining sub-sample.

2. The dependent variable is a dummy variable that equals 1 if the customer took up at least one loan by the stated deadline on the offer letter, 0 otherwise.

3. "Suggestion call (treated)" is a dummy variable that equals 1 is the customer actually received a suggestion phone call, 0 otherwise. In the IV regressions, we instrument the "Suggestion call (treated)" with "Suggestion call (attempted)." See text for details.

4. Each column corresponds to the estimation of a probit model, unless noted IV. Reported in the table are marginal effects. For each column, reported under brackets is the ratio of the estimated effect of the psychological intervention on take-up to the estimated effect of the interest rate on take-up.

5. "Customer characteristics" include: dummy variables for the number of months the client's account at the Lender has been dormant, the logarithm of the number of months the client has been employed at his or her current employer, the logarithm of the client's gross monthly income, the client's external credit score (and a dummy variable for the external credit score zero being zero, which implies missing), a gender dummy, a dummy variable for the client having a high education background, dummy variables for the client's province of residence, dummy variables for the client's first language, the client's number of dependents (and a dummy for the client having no dependents), and a dummy variable for a client having both cellular and home phone numbers invalid.

6. "Risk category F.E." are fixed effects for the 3 risk categories among borrowers (high, medium, low). "Experimental wave F.E." are fixed effects for the 2 experimental waves (September and October). See text for details. 
Table 9

Effect of Suggested Loan Usage on Reported Usage ${ }^{a}$

Loan to Be Used for:

\begin{tabular}{|c|c|c|c|c|c|c|}
\hline & & & & & & \multirow[b]{2}{*}{$\begin{array}{c}\text { Expected } \\
\text { Distribution }\end{array}$} \\
\hline & House & School & Debt & Appliances & Other & \\
\hline Suggested Money Usage is: & (1) & $(2)$ & (3) & $(4)$ & $(5)$ & (6) \\
\hline House & $\begin{array}{c}24.03 \% \\
+\mathbf{3 . 0 0 \%}\end{array}$ & $\begin{array}{l}21.69 \% \\
+0.67 \%\end{array}$ & $\begin{array}{l}21.12 \% \\
+0.09 \%\end{array}$ & $\begin{array}{l}20.83 \% \\
-0.19 \%\end{array}$ & $\begin{array}{l}20.26 \% \\
-0.77 \%\end{array}$ & $21.02 \%$ \\
\hline Education & $\begin{array}{l}19.48 \% \\
+0.85 \%\end{array}$ & $\begin{array}{c}21.69 \% \\
+\mathbf{3 . 0 6 \%}\end{array}$ & $\begin{array}{l}17.39 \% \\
-1.24 \%\end{array}$ & $\begin{array}{l}20.83 \% \\
+2.20 \%\end{array}$ & $\begin{array}{l}17.68 \% \\
-0.95 \%\end{array}$ & $18.63 \%$ \\
\hline Pay off debt & $\begin{array}{l}16.88 \% \\
-2.50 \%\end{array}$ & $\begin{array}{l}17.28 \% \\
-2.11 \%\end{array}$ & $\begin{array}{c}22.98 \% \\
+\mathbf{3 . 6 0 \%}\end{array}$ & $\begin{array}{l}16.67 \% \\
-2.72 \%\end{array}$ & $\begin{array}{l}19.91 \% \\
+0.52 \%\end{array}$ & $19.39 \%$ \\
\hline Appliance & $\begin{array}{l}16.23 \% \\
-4.11 \%\end{array}$ & $\begin{array}{l}18.75 \% \\
-1.59 \%\end{array}$ & $\begin{array}{l}21.74 \% \\
+1.40 \%\end{array}$ & $\begin{array}{c}20.83 \% \\
+\mathbf{0 . 4 9 \%}\end{array}$ & $\begin{array}{l}21.31 \% \\
+0.97 \%\end{array}$ & $20.34 \%$ \\
\hline Generic & $\begin{array}{l}23.38 \% \\
+2.76 \%\end{array}$ & $\begin{array}{l}20.59 \% \\
-0.03 \%\end{array}$ & $\begin{array}{l}16.77 \% \\
-3.84 \%\end{array}$ & $\begin{array}{l}20.83 \% \\
+0.22 \%\end{array}$ & $\begin{array}{l}20.84 \% \\
+0.23 \%\end{array}$ & $20.61 \%$ \\
\hline Sample size & 154 & 272 & 161 & 24 & 854 & 1465 \\
\hline Joint $\mathrm{P}$ value: & & & & & & 0.0587 \\
\hline
\end{tabular}

${ }^{a}$ Notes:

1. Sample is the subset of $(1,465)$ customers who took up a loan and were asked by the bank officer to report their planned usage for the loan. See text for details. This sample is broken down into five subgroups (columns) based on customers' reported loan usage. For a given reported usage, customers are further broken down into five subgroups (rows) based on the suggested loan usage they received in their offer letter. See text for details.

2. Reported at the top of each cell is the fraction of customers reporting that (column) loan usage that were assigned that (row) suggested loan usage. Reported at the bottom of each cell is the difference between this fraction and the fraction of customers that were assigned that (row) suggested loan usage (as reported in the last column).

3. Under the null of "no suggestion effect," suggested loan usages should have no effect on the reported loan usages. For example, for the 154 customers who used their loan to pay for house-related expenses, we would expect, under the null, that $21.0 \%$ of them had received letters suggesting using the money for house expenses, $18.6 \%$ for education expenses, $19.4 \%$ to repay other debt and $20.3 \%$ for buying appliances. In other words, under the null of "no suggestion effect," the actual distributions in columns (1) to (4) should match the expected distribution (last column).

4. Reported in the table is the P-value for a joint test of these four actual distributions of loan usage differing from the expected distribution. 
Table 10

Additive Effects of Interventions on Loan Take-Up ${ }^{a}$

Dependent Variable: Take-Up Dummy

Sample:

All

High Attention

All Interventions Sig. Interventions All Interventions Sig. Interventions

Female photo

0.177

0.669

0.648

1.165

$\Delta$ interest rate equivalent

Opposite gender photo

0.141

0.611

0.656

1.190

$\Delta$ interest rate equivalent

Female photo for male customer

0.201

0.812

[2.01]

0.774

1.376

$[0.77]$

[3.12]

$(0.267)$

$\Delta$ interest rate equivalent

[2.38]

${ }^{a}$ Notes:

1. Sample is the entire set of customers that were mailed the experimental loan offer, excluding those for which the offer letter was returned to the Lender.

2. The dependent variable is a dummy variable that equals 1 if the customer took up at least one loan by the stated deadline on the offer letter, 0 otherwise.

3. Each cell in the table corresponds to a different probit model. Reported in each cell is the marginal effect on the treatment intensity variable as defined by that row and column. In brackets is the ratio of the estimated effect of the treatment intensity on take-up to the estimated effect of the interest rate on take-up. All models also control for risk category fixed effects and experimental wave fixed effects.

4. The different treatment intensity variables are defined as follows. Under "All interventions" (columns 1 and 3 ), the treatment intensity is defined as "small option table" + "race photo match"- "no comparison of offer to competitor" - "promotional lottery." In addition, we either code a female photo (row 1), a photo of the opposite gender of the customers gender (row 2) or a female photo sent to a male customer (row 3) as " +1 ." Under "Sig. interventions" (column 2 and 4), the treatment intensity variable is defined as "small option table" - "promotional lottery for high attention customers" + "loss comparison for the total monthly savings comparison frame for high attention customers" + "gain comparison for the remaining comparison frames for high attention customers". In addition, we either code a female photo (row 1), a photo of the opposite gender of the customers gender (row 2) or a female photo sent to a male customer (row 3) as "+1." See text and notes to earlier tables for details. 


\title{
Table 11 Additive Effects of Interventions on Loan Take-Up Non-Linearities ${ }^{a}$
}

\author{
Dependent Variable: Take-Up Dummy
}

\section{Sample:}

Weighted number of interventions

Weighted number of interventions ${ }^{2}$

Spline 1 of weighted $n$. of interventions

Spline 2 of weighted $n$. of interventions

Net number of interventions $=-2$

Net number of interventions $=-1$

Net number of interventions $=0$

Net number of interventions $=1$

Net number of interventions $=2$

Net number of interventions $=3$

Interest rate

Risk category F.E.?

Experimental wave F.E.?
All

All

Interventions
(2)

(3)

0.641

(.122)

18.466

(21.837)
(4)

(5)

(6)

(7)

High Attention

Significant Interventions Only

1.031

(.396)

$-9.052$

(15.13)

omitted

1.075
$(1.126)$

omitted

1.376

(1.058)

1.670

(1.059)

1.937

(1.182)

2.505

(1.489)

$-0.257$

(.049)

yes

yes
0.852

(.583)

1.409

(.577)

1.375

(.793)

5.898

(2.199)

$-0.258$

(.049)

yes

yes
0.440

$(.289)$

0.802

(.173)

1.329

(.574)

0.586

omitted

1.905

(.990)

2.939

(1.002)

4.913

(1.352)

7.234

(3.004)

$\begin{array}{lllll}-0.257 & -0.257 & -0.322 & -0.320 & -0.320 \\ (.049) & (.049) & (.145) & (.145) & (.145)\end{array}$

$\begin{array}{lllll}-0.257 & -0.257 & -0.322 & -0.320 & -0.320 \\ (.049) & (.049) & (.145) & (.145) & (.145)\end{array}$

yes yes yes yes yes

yes yes yes yes yes

${ }^{a}$ Notes:

1. Sample is the entire set of customers that were mailed the experimental loan offer, excluding those for which the offer letter was returned to the Lender.

2. The dependent variable is a dummy variable that equals 1 if the customer took up at least one loan by the stated deadline on the offer letter, 0 otherwise.

3. "All interventions" (column 1), the treatment intensity is defined as "small option table" + "race photo match" + "female photo for male customer" - "no comparison of offer to competitor" - "promotional lottery." Significant interventions only (columns 2-7) is defined as "small option table" + "female photo for male customer"""promotional lottery for high attention customers" + "loss comparison for the total monthly savings comparison frame for high attention customers" + "gain comparison for the remaining comparison frames for high attention customers". In column 2 and 5, we create dummy variables corresponding to all possible values of the treatment intensity variables. For "weighted number of interventions," (columns 3 and 6) each of the single interventions listed above is weighted by its marginal effect on take-up as estimated in the single probit regressions above (Tables 3 to 7 ). See text and notes to earlier tables for details. For columns 4 and 7 , we spline the "weighted number of interventions" at its median; we estimate separate coefficients for below median (spline 1) and above median (spline 2).

4. "Risk category F.E." are fixed effects for the 3 risk categories among borrowers (high, medium, low). "Experimental wave F.E." are fixed effects for the 2 experimental waves (September and October).

5. Each column corresponds to the estimation of a probit model. Reported in the table are marginal effects. 
Table 12

Interaction of Psychological Interventions with Interest Rate ${ }^{a}$

Dependent Variable: Take-Up Dummy

All Interventions Sig. Interventions

Net number of interventions

$-0.007$

0.545

Interventions*high rate

0.454

0.585

High rate

$-1.307$

$-1.398$

Risk category F.E.?

yes

Experimental wave F.E.?

yes

yes

yes

${ }^{a}$ Notes:

1. Sample is the entire set of customers that were mailed the experimental loan offer, excluding those for which the offer letter was returned to the Lender.

2. The dependent variable is a dummy variable that equals 1 if the customer took up at least one loan by the stated deadline on the offer letter, 0 otherwise.

3. The different treatment intensity variables are defined as follows. Under "All interventions" (column 1), the treatment intensity is defined as "small option table" + "race photo match" + "female photo for male customer" - "no comparison of offer to competitor" - "promotional lottery." Under "Sig. interventions" (column 2 ), the treatment intensity variable is defined as "small option table" + "female photo for male customer""promotional lottery for high attention customers" + "loss comparison for the total monthly savings comparison frame for high attention customers" + "gain comparison for the remaining comparison frames for high attention customers". See text and notes to earlier tables for details.

4. "High rate" is a dummy variable that equals 1 if the offer interest rate was above median in the borrowers risk category, 0 otherwise.

5. "Risk category F.E." are fixed effects for the 3 risk categories among borrowers (high, medium, low). "Experimental wave F.E." are fixed effects for the 2 experimental waves (September and October). See text for details.

6. Each column corresponds to the estimation of a probit model. Reported in the table are marginal effects. 


\title{
Table 13 Effects of Interventions on Loan Take-Up by Customer Characteristics ${ }^{a}$
}

\author{
Dependent Variable: Take-Up Dummy
}

\begin{tabular}{|c|c|c|c|c|}
\hline & \multicolumn{2}{|c|}{ All Interventions } & \multicolumn{2}{|c|}{ Sig. Interventions } \\
\hline & $(1)$ & $(2)$ & $(3)$ & (4) \\
\hline Net number of interventions & $\begin{array}{l}0.237 \\
(.162)\end{array}$ & $\begin{array}{l}0.182 \\
(.153)\end{array}$ & $\begin{array}{l}0.772 \\
(.219)\end{array}$ & $\begin{array}{l}0.828 \\
(.211)\end{array}$ \\
\hline Interventions*high education & $\begin{array}{c}-0.070 \\
(.217)\end{array}$ & & $\begin{array}{l}0.078 \\
(.296)\end{array}$ & \\
\hline Interventions*high income & & $\begin{array}{l}0.036 \\
(.216)\end{array}$ & & $\begin{array}{r}-0.031 \\
(.295)\end{array}$ \\
\hline Interest rate & $\begin{array}{r}-0.212 \\
(.075)\end{array}$ & $\begin{array}{r}-0.246 \\
(.069)\end{array}$ & $\begin{array}{r}-0.212 \\
(.075)\end{array}$ & $\begin{array}{r}-0.246 \\
(.069)\end{array}$ \\
\hline Risk category F.E.? & yes & yes & yes & yes \\
\hline Experimental wave F.E.? & yes & yes & yes & yes \\
\hline Sample size & 53194 & 53194 & 53194 & 53194 \\
\hline
\end{tabular}

${ }^{a}$ Notes:

1. Sample is the entire set of customers that were mailed the experimental loan offer, excluding those for which the offer letter was returned to the Lender.

2. The dependent variable is a dummy variable that equals 1 if the customer took up at least one loan by the stated deadline on the offer letter, 0 otherwise.

3. The different treatment intensity variables are defined as follows. Under "All interventions" (columns 1$2)$, the treatment intensity is defined as "small option table" + "race photo match" + "female photo for male customer" - "no comparison of offer to competitor" - "promotional lottery." Under "Sig. interventions" (column 3), the treatment intensity variable is defined as "small option table" + "female photo for male customer"- "promotional lottery for high attention customers" + "loss comparison for the total monthly savings comparison frame for high attention customers" + "gain comparison for the remaining comparison frames for high attention customers". See text and notes to earlier tables for details.

4. "High education" is a dummy variable that equals 1 if the customer has a predicted number of years of education that is above the sample median. "High income" is a dummy variable that equals 1 if the customer has an monthly gross income level that is above the sample median.

5. "Risk category F.E." are fixed effects for the 3 risk categories among borrowers (high, medium, low). "Experimental wave F.E." are fixed effects for the 2 experimental waves (September and October). Also included in each regression is a vector of controls conditional on which the interventions were randomly assigned and the direct effect of education or income, depending on the column. See text for details.

6. Each column corresponds to the estimation of a probit model. Reported in the table are marginal effects. 
Table 14

Effects of Interventions on Loan Repayment ${ }^{a}$

Dependent Variable: Past Due Amount as a Percent of Total Loan Amount

Baseline All Interventions Sig. Interventions

\begin{tabular}{|c|c|c|c|c|c|}
\hline \multirow[t]{2}{*}{ Sample: } & All & All & Female & Male & All \\
\hline & (1) & $(2)$ & (3) & (4) & $(5)$ \\
\hline \multirow[t]{3}{*}{ erventions } & & $\begin{array}{c}-0.284 \\
(.752)\end{array}$ & $\begin{array}{c}0.782 \\
(1.116)\end{array}$ & $\begin{array}{c}-1.007 \\
1.020\end{array}$ & $\begin{array}{l}-0.46 \\
(0.99)\end{array}$ \\
\hline & 1.221 & 1.214 & 1.494 & 0.464 & 0.99 \\
\hline & $(.353)$ & $(.478)$ & $(.632)$ & $(.712)$ & (.48) \\
\hline \multirow{3}{*}{$\begin{array}{l}? \\
\text { F.E.? }\end{array}$} & yes & yes & yes & yes & yes \\
\hline & yes & yes & yes & yes & yes \\
\hline & 3944 & 3944 & 1946 & 1998 & 3944 \\
\hline
\end{tabular}

${ }^{a}$ Notes:

1. Sample is the set of customers that have taken-up at least one loan by the deadline assigned to their offer letter. This sample is broken by gender in columns 3 and 4 .

2. The dependent variable is the amount past due on the loan as a percentage of the total loan amount.

3. The different treatment intensity variables are defined as follows. Under "All interventions" (columns 14 ), the treatment intensity is defined as "small option table" + "race photo match" + "female photo for male customer" - "no comparison of offer to competitor" - "promotional lottery." Under "Sig. interventions" (column 5), the treatment intensity variable is defined as "small option table" + "female photo for male customer"- "promotional lottery for high attention customers" + "loss comparison for the total monthly savings comparison frame for high attention customers" + "gain comparison for the remaining comparison frames for high attention customers". See text and notes to earlier tables for details.

4. "Risk category F.E." are fixed effects for the 3 risk categories among borrowers (high, medium, low). "Experimental wave F.E." are fixed effects for the 2 experimental waves (September and October). See text for details.

5. Each column corresponds to the estimation of a tobit model. 
Table 15

Effects of Interventions on Other Borrowing ${ }^{a}$

\author{
Dependent Variable: Total Other Debt Taken Out \\ Amount \\ Dummy
}

All Interventions Sig. Interventions All Interventions Sig. Interventions

Net number of interventions

49.26

(225.85)

111.27

$-254.5$

(352.80)

111.45

0.03

$(0.21)$

0.03

$-0.188$

Interest rate

Risk category F.E.?

yes

yes

yes

yes

Experimental wave F.E.?

yes

yes

yes

yes

Sample size

53194

53194

53194

53194

${ }^{a}$ Notes:

1. Sample is the entire set of customers that were mailed the experimental loan offer, excluding those for which the offer letter was returned to the Lender.

2. The dependent variable for columns 1-3 is total debt taken out over a six-month period after the mailing of the offer Lender, either from other lenders or from the Lender (but excluding pre-deadline borrowing from the Lender). The dependent variable in columns 4-6 is a dummy for having taken out any loan over a sixmonth period after the mailing of the offer letter, either from other lenders or from the Lender (but excluding pre-deadline borrowing from the Lender).

3. The different treatment intensity variables are defined as follows. Under "All interventions" (columns 1 and 3 ), the treatment intensity is defined as "small option table" + "race photo match" + "female photo for male customer" - "no comparison of offer to competitor" - "promotional lottery." Under "Sig. interventions" (columns 2 and 4), the treatment intensity variable is defined as "small option table" + "female photo for male customer" - "promotional lottery for high attention customers" + "loss comparison for the total monthly savings comparison frame for high attention customers" + "gain comparison for the remaining comparison frames for high attention customers". See text and notes to earlier tables for details.

4. "Risk category F.E." are fixed effects for the 3 risk categories among borrowers (high, medium, low). "Experimental wave F.E." are fixed effects for the 2 experimental waves (September and October). See text for details.

5. Columns 1-2 correspond to the estimation of tobit models; columns 3-4 correspond to the estimation of probit models. 


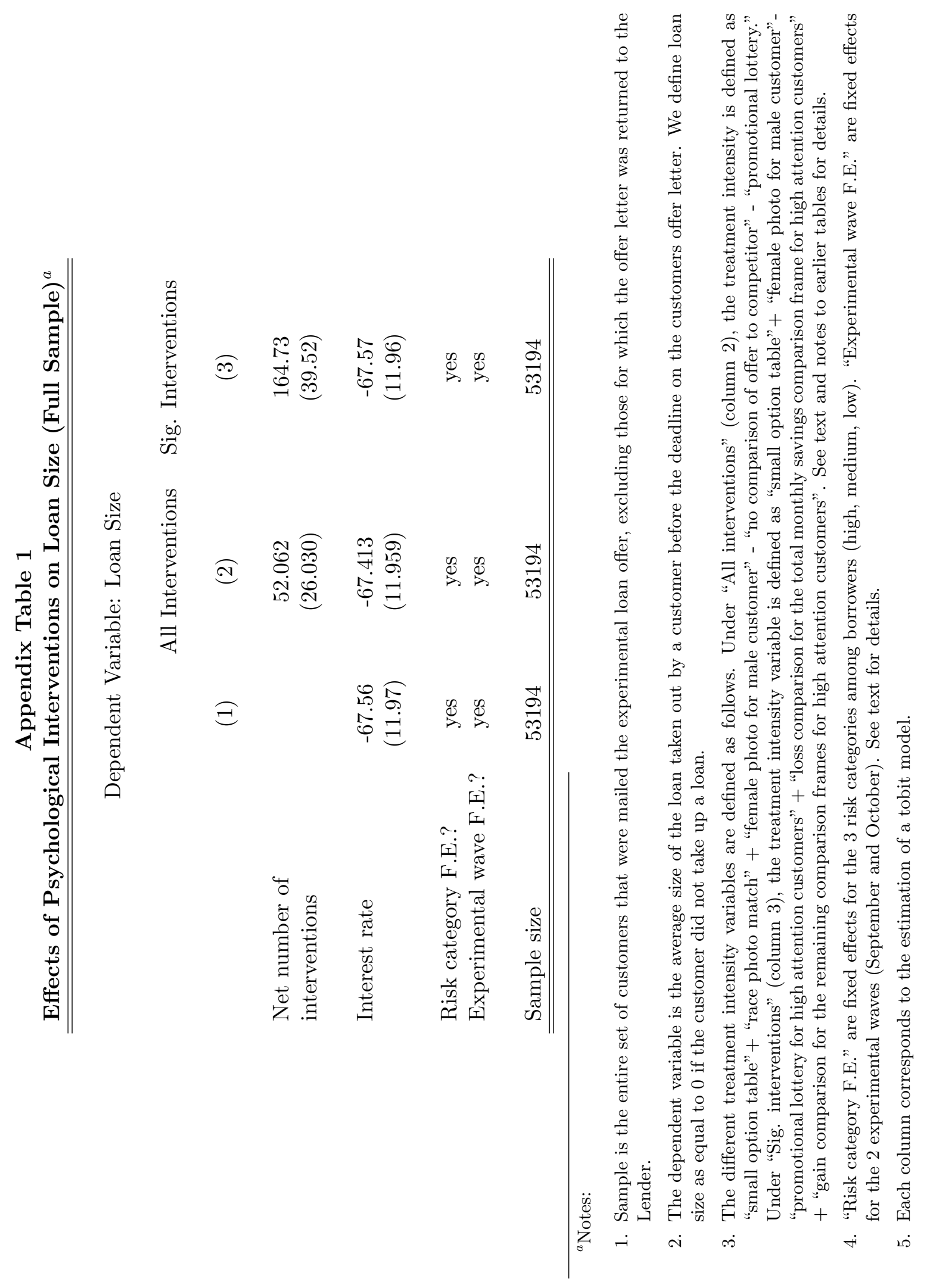




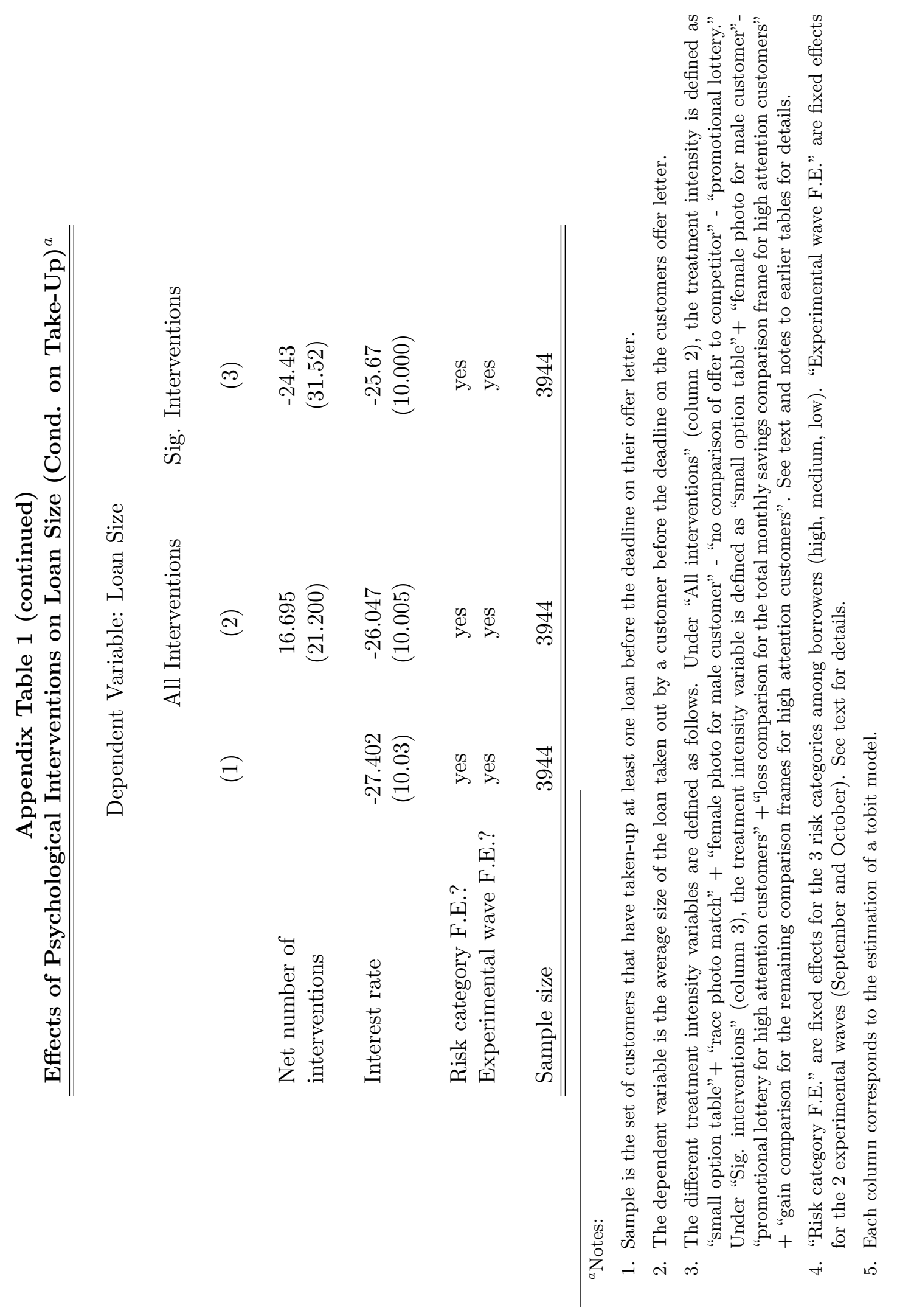




\section{Appendix Table 2 \\ Interaction of Psychological Interventions with Interest Rate: Selection ${ }^{a}$}

Dependent Variable: Predicted Price Sensitivity

All interventions Sig. Interventions

Net number of interventions

$-.000087$

$-.00017$

$(.00033)$

Risk category F.E.?

Experimental wave F.E.?

$\begin{array}{ll}\text { yes } & \text { yes } \\ \text { yes } & \text { yes }\end{array}$

3844

3844

${ }^{a}$ Notes:

1. Sample is the set of customers that took up at least one loan by the stated deadline on their offer letter.

2. The dependent variable, "Predicted price sensitivity," was constructed as follows. Using the full sample, we regressed the take-up dummy on the vector of customer characteristics (see below for list), a "high interest" rate dummy variable (equals to 1 if the offer interest rate was above median in the customers risk category), risk category fixed effects, experimental wave fixed effects, and a full set of interactions between the "high interest" rate dummy and customer characteristics. We then computed, for each customer, predicted take-up under high interest rate and predicted take-up under low interest rate. The dependent variable is defined as predicted take-up under low interest rate minus predicted take-up under high interest rate.

3. The customer characteristics include: dummy variables for the number of months the client's account at the Lender has been dormant, the logarithm of the number of months the client has been employed at his or her current employer, the logarithm of the client's gross monthly income, the client's external credit score (and a dummy variable for the external credit score zero being zero, which implies missing), a gender dummy, a dummy variable for the client having a high education background, dummy variables for the client's province of residence, dummy variables for the client's first language, the client's number of dependents (and a dummy for the client having no dependents), and a dummy variable for a client having both cellular and home phone numbers invalid.

4. The different treatment intensity variables are defined as follows. Under "All interventions" (column 1), the treatment intensity is defined as "small option table" + "race photo match" + "female photo for male customer" - "no comparison of offer to competitor" - "promotional lottery." Under "Sig. interventions" (column $3)$, the treatment intensity variable is defined as "small option table" + "female photo for male customer""promotional lottery for high attention customers" + "loss comparison for the total monthly savings comparison frame for high attention customers" + "gain comparison for the remaining comparison frames for high attention customers". See text and notes to earlier tables for details.

5. "Risk category F.E." are fixed effects for the 3 risk categories among borrowers (high, medium, low). "Experimental wave F.E." are fixed effects for the 2 experimental waves (September and October). See text for details.

6. Each column corresponds to the estimation of an OLS model. 


\section{Appendix Table 3 Summary of Customers Characteristics: Intent to Treat Group for Suggestion Call ${ }^{a}$}

\begin{tabular}{|c|c|c|}
\hline \multirow[t]{2}{*}{ Variable } & No Attempt at Suggestion Call & Attempt at Suggestion Call \\
\hline & $(1)$ & $(2)$ \\
\hline \multirow[t]{2}{*}{ Male } & 0.525 & 0.523 \\
\hline & $(0.50)$ & $(0.50)$ \\
\hline \multirow[t]{2}{*}{ Black } & 0.841 & 0.873 \\
\hline & $(0.37)$ & $(0.33)$ \\
\hline \multirow[t]{2}{*}{ Coloured } & 0.041 & 0.037 \\
\hline & $(0.20)$ & $(0.19)$ \\
\hline \multirow[t]{2}{*}{ Indian } & 0.012 & 0.012 \\
\hline & $(0.11)$ & $(0.11)$ \\
\hline \multirow[t]{2}{*}{ White } & 0.107 & 0.078 \\
\hline & $(0.31)$ & $(0.27)$ \\
\hline \multirow[t]{2}{*}{ Low risk } & 0.770 & 0.770 \\
\hline & $(0.42)$ & $(0.42)$ \\
\hline \multirow[t]{2}{*}{ Medium risk } & 0.117 & 0.112 \\
\hline & $(0.32)$ & $(0.32)$ \\
\hline \multirow[t]{2}{*}{ High risk } & 0.114 & 0.117 \\
\hline & $(0.32)$ & $(0.32)$ \\
\hline Months since & 10.026 & 9.907 \\
\hline last loan & $(6.67)$ & $(6.69)$ \\
\hline Previous number & 3.522 & 3.518 \\
\hline of loans & $(3.04)$ & $(3.21)$ \\
\hline English is & 0.564 & 0.575 \\
\hline first language & $(0.50)$ & $(0.50)$ \\
\hline Gross monthly & 3689.122 & 3444.306 \\
\hline income (rands) & $(26928.32)$ & $(2525.74)$ \\
\hline $\begin{array}{l}\text { Predicted education } \\
\text { (years) }\end{array}$ & $\begin{array}{l}7.429 \\
(2.76)\end{array}$ & $\begin{array}{l}7.270 \\
(2.77)\end{array}$ \\
\hline Log (months at & 3.983 & 3.892 \\
\hline current Employer) & $(1.13)$ & $(1.19)$ \\
\hline credit score & 585.675 & 585.152 \\
\hline Number of & 1.510 & 1.528 \\
\hline dependents & $(1.54)$ & $(1.48)$ \\
\hline Sample Size & 28304 & 409 \\
\hline
\end{tabular}

${ }^{a}$ Notes:

1. "No Attempt at Suggestion Call" is the sub-sample of customers that were eligible for a suggestion phone call but not did not receive a suggestion phone call. "Attempt at Suggestion Call" is the sub-sample of customers that were eligible for a suggestion phone call and received such a call. Only a portion of this second sub-sample was actually reached (148 of 409).

2. Reported in the table are means and standard deviations (in parentheses). 


\section{A low rate for you.}

Congratulations! As a valued client, you are now eligible for a low interest rate on your next cash loan from This is a limited time offer, so please come in by 30 November 2003 to take advantage of this offer.

You can use this cash to pay for school, or for anything else you want.

$\because$ Enjoy low monthly repayments with this offer! Here is one example of a loan you can get under this offer:

\begin{tabular}{|c|c|c|c|}
\hline $\begin{array}{c}\text { Interest } \\
\text { Rate }\end{array}$ & \multicolumn{1}{c}{$\begin{array}{c}\text { Loan } \\
\text { Amount }\end{array}$} & $\begin{array}{c}\text { Loan } \\
\text { Term }\end{array}$ & $\begin{array}{c}\text { Monthly } \\
\text { Repayment }\end{array}$ \\
\hline $10.50 \%$ & R2000.00 & 4 Months & R710.00 \\
\hline
\end{tabular}

LOAN AVAILABILITY SUBUECT TO TERMS \& CONDITIONS

Loans available in other amounts. There are no hidden costs. What you see is what you pay.

If you borrow elsewhere you will pay $\mathbf{R} 360.00$ more in total on a R2000.00, 4 month loan.

\section{How to apply:}

Bring your ID book and latest payslip to your usual branch, by 30 November 2003 and ask for 


\section{the trusted way to borrow cash}

25 September 2003

\section{A low rate for you.}

Congratulations! You are now eligible for a special interest rate on a cash loan from 1. This is a limited time offer, so please come in by 31 October 2003

You can use this cash to pay off a more expensive debt, or for anything else you want.

$\because$ Enjoy low monthly repayments with this offer! For example:

\begin{tabular}{|c|c|c|c|}
$\begin{array}{c}\text { Interest } \\
\text { Rate }\end{array}$ & \multicolumn{1}{c}{$\begin{array}{c}\text { Loan } \\
\text { Amount }\end{array}$} & \multicolumn{1}{c}{$\begin{array}{c}\text { Loan } \\
\text { Term }\end{array}$} & \multicolumn{1}{c|}{$\begin{array}{c}\text { Monthly } \\
\text { Repayment }\end{array}$} \\
\hline $3.99 \%$ & R500 & 4 Months & R144.95 \\
\hline $3.99 \%$ & R1000 & 4 Months & R289.90 \\
\hline $3.99 \%$ & R2000 & 4 Months & R579.80 \\
\hline $3.99 \%$ & R4000 & 4 Months & R1159.60 \\
\hline
\end{tabular}

Loans available in other amounts. There are no hidden costs. What you see is what you pay.

If you borrow from us you will pay $\mathbf{R} 840.40$ less in total on a R1000.00, 4 month loan.

\section{How to apply:}

Bring your ID book and latest payslip to your usual branch, by

31 October 2003 and ask for I 


\section{the trusted way to borrow cash}

25 September 2003

Account Number

\section{A special rate for you.}

Dear

Congratulations! You are now eligible for a special interest rate on a cash loan from ( .... This is a limited time offer, so please come in by 31 October 2003

You can use this cash to pay off a more expensive debt, or for anything else you want.

$\because$ Enjoy low monthly repayments with this offer! Here is one example of a loan you can get under this offer:

\begin{tabular}{|c|c|c|}
\hline \multicolumn{1}{|c}{$\begin{array}{c}\text { Loan } \\
\text { Amount }\end{array}$} & \multicolumn{1}{c}{$\begin{array}{c}\text { Loan } \\
\text { Term }\end{array}$} & $\begin{array}{c}\text { Monthly } \\
\text { Repayment }\end{array}$ \\
\hline R1000.00 & 4 Months & R379.90 \\
\hline
\end{tabular}

LOAN AVAILABILITY SUBJECT TO TERMS \& CONDITIONS

Loans available in other amounts. There are no hidden costs. What you see is what you pay.

\section{How to apply:}

Bring your ID book and latest payslip to your usual branch, by 31 October 2003 and ask for ' 